\title{
Influence of the Background Wind on the Local Soil Moisture-Precipitation Feedback
}

\author{
PAUL FROIDEVAUX \\ Institute for Atmospheric and Climate Science, ETH Zürich, Zurich, and Oeschger Centre for Climate Change Research \\ and Institute of Geography, University of Bern, Bern, Switzerland
}

LINDA SCHLEMMER

Max Planck Institute for Meteorology, Hamburg, Germany

JUERG SCHMIDLI

Institute for Atmospheric and Climate Science, ETH Zürich, Zurich, Switzerland

WOLFGANG LANGHANS

Earth Sciences Division, Lawrence Berkeley National Laboratory, Berkeley, California, and Centre for Climate Systems Modeling (C2SM), Zurich, Switzerland

CHRISTOPH SCHÄR

Institute for Atmospheric and Climate Science, ETH Zürich, Zurich, Switzerland

(Manuscript received 14 June 2013, in final form 26 August 2013)

\begin{abstract}
The importance of soil moisture anomalies on airmass convection over semiarid regions has been recognized in several studies. The underlying mechanisms remain partly unclear. An open question is why wetter soils can result in either an increase or a decrease of precipitation (positive or negative soil moistureprecipitation feedback, respectively). Here an idealized cloud-resolving modeling framework is used to explore the local soil moisture-precipitation feedback. The approach is able to replicate both positive and negative feedback loops, depending on the environmental parameters.

The mechanism relies on horizontal soil moisture variations, which may develop and intensify spontaneously. The positive expression of the feedback is associated with the initiation of convection over dry soil patches, but the convective cells then propagate over wet patches where they strengthen and preferentially precipitate. The negative feedback may occur when the wind profile is too weak to support the propagation of convective features from dry to wet areas. Precipitation is then generally weaker and falls preferentially over dry patches. The results highlight the role of the midtropospheric flow in determining the sign of the feedback. A key element of the positive feedback is the exploitation of both low convective inhibition (CIN) over dry patches (for the initiation of convection) and high CAPE over wet patches (for the generation of precipitation).
\end{abstract}

\section{Introduction}

Interactions between the land surface and deep convection play a major role for weather and climate (Pielke 2001; Betts 2004, 2009). Feedbacks between soil moisture

Corresponding author address: Paul Froidevaux, Institute of Geography, University of Bern, Hallerstrasse 12, 3012 Bern, Switzerland.

E-mail: paul.froidevaux@giub.unibe.ch and precipitation (SMP feedbacks) are believed to be of particular importance in the transition zones between dry and wet climatic regions. Over such regions evaporation is mainly limited by soil moisture (Koster et al. 2004), which controls the partitioning of the surface energy flux into heat and moisture. These surface fluxes determine the diurnal evolution of the planetary boundary layer (PBL) and thereby influence the formation of airmass convection. Deep convection can then produce rainfall, shape the future soil moisture distribution, and

DOI: 10.1175/JAS-D-13-0180.1

(C) 2014 American Meteorological Society 
potentially generate a closed feedback loop. SMP feedbacks have been found to be relevant at a broad range of scales, from the continental climate and its variability (Schär et al. 1999; Findell and Eltahir 2003a; Schär et al. 2004; Seneviratne et al. 2006; Findell et al. 2011; Schlemmer et al. 2012) down to the scale of a single thunderstorm (Clark et al. 2004; Taylor et al. 2011a; Barthlott and Kalthoff 2011). SMP feedbacks at convective scales represent a major challenge for numerical weather prediction, especially for the prediction of storms over homogeneous terrain where soil moisture variations account for most of the surface variability. A clear understanding of the multitude of involved scales is lacking. While a convective-scale mechanism could, in principle, govern the large-scale feedbacks, it has also been argued that even the sign of the SMP feedbacks may depend upon the scale considered (Emori 1998). In this study we will address the SMP feedbacks at convective scales $[O(10 \mathrm{~km})]$ and for brevity refer to these as the local SMP feedbacks.

A peculiarity of the local SMP feedbacks is the relevance of mesoscale circulations induced by horizontal variations of surface fluxes (see Segal and Arritt 1992). In analogy to sea-breeze circulations, horizontal variations of the PBL's thermodynamic state can trigger atmospheric circulations with upward motions over drier and warmer surfaces (Ookouchi et al. 1984; Segal and Arritt 1992; Avissar and Liu 1996). These circulations support the formation of deep cumulus convection (Pielke 2001; Garcia-Carreras et al. 2011). Weaver and Avissar (2001) and Baidya Roy and Avissar (2002) relate observations of cumulus development over the U.S. central plains and Amazonia to local circulations developing over human-induced land surface inhomogeneities. Taylor et al. (2007) observed soil moistureinduced mesoscale circulations over the Sahel region using aircraft measurements and satellite data. Consistent with soil moisture-driven circulations, they found zones of low-level divergence (convergence) over patches of wet (dry) soil. Avissar and Liu (1996) and Kang and Bryan (2011) performed high-resolution simulations of convection initiation over surfaces of specified soil moisture and surface flux heterogeneity, respectively. They both found that moist convection is initiated first over areas with high sensible heat flux, typically corresponding to dry areas.

However, while the control of soil moisture patchiness on evaporation and PBL evolution is quite well established, the second part of the feedback loop, involving the effect of PBL variability on the precipitation distribution, is more complex. Clear evidence for the whole SMP feedback is still missing for midlatitudes because the control of local soil moisture on local precipitation is difficult to constrain in observations and contradictory conclusions have been documented (Findell and Eltahir 1997; Salvucci et al. 2002). Nevertheless, evidence for SMP feedbacks has been shown for the Sahel region. Taylor and Lebel (1998) found persistent rainfall gradients in rain gauge data obtained during the HydrologyAtmosphere Pilot Experiment (HAPEX) field campaign (Goutorbe et al. 1994). They could link this phenomenon to wet soil anomalies locally enhancing convection in passing storms, and therefore to a positive SMP feedback. On the other hand, Taylor and Ellis (2006) found a negative correlation between soil moisture and convective clouds by analyzing satellite data. Schwendike et al. (2010) moreover observed that convective precipitation and the resulting soil moisture increase can diminish the conditions favorable to the triggering of subsequent convection within 2-3 days.

These and other publications indicate that both a positive and a negative feedback occur in nature, and a number of hypothesis have been put forward: Findell and Eltahir (2003a), who investigated the SMP feedback at a larger scale, argued that the atmospheric stability and low-level humidity determine whether convection initiation is more likely to occur over wetter or drier soils. Using explicit simulations of convection, early idealized numerical studies demonstrated a negative local SMP feedback (Avissar and Liu 1996; Emori 1998), but Clark et al. (2004) who simulated squall lines found a more complex response with both suppression and enhancement of rainfall over wet areas. Real-case simulations showed that a positive SMP feedback can exist for mature convective systems (Gantner and Kalthoff 2010; Wolters et al. 2010), whereas a negative feedback was found for the triggering of convection (Gantner and Kalthoff 2010).

We still lack an explanation for the different local SMP feedbacks reported and our understanding remains limited by the impossibility of resolving the underlying processes in current climate simulations. All aforementioned numerical studies, except the $2 \mathrm{D}$ simulations of Emori (1998), focused either on one particular storm, and/or did not consider the complete feedback cycle (i.e., by using prescribed soil conditions). As suggested by Clark et al. (2004, p. 639), "[t]he final steps in this work would be to use a fully coupled model to simulate all aspects of the soil moisture-rainfall feedback loop over several storms, to investigate whether rainfall persistence emerges."

Here we employ such a setup and investigate the SMP feedbacks using cloud-resolving simulations in a framework with a fully coupled land surface and over time periods of several weeks to represent the successive development of rain-producing storms in an idealized environment. We postulate that the differences between positive and negative feedbacks are related to the wind profiles. 
The model used and the experimental setup are introduced in section 2. Results from simulations with different background wind speeds are presented in section 3. A discussion using conceptual models and conclusions are given in sections 4 and 5 , respectively.

\section{Setup of numerical experiment}

\section{a. Model description}

The model used in this study is the Consortium for Small-Scale Modeling (COSMO) model in climate mode (hereafter CCLM). It is a versatile limited-area atmospheric modeling system including a whole suite of model parameterizations (Steppeler et al. 2003; Doms and Förstner 2004). It is based on the nonhydrostatic compressible atmospheric equations and uses the splitexplicit time-stepping scheme (Klemp and Wilhelmson 1978; Wicker and Skamarock 2002). The model is used in different configurations for operational numerical weather prediction purposes at several European Weather Services (http://www.cosmo-model.org/) and has been further developed into a regional climate modeling system (see Rockel et al. 2008).

The model setup has been adapted specifically to the convective scale (Baldauf et al. 2011). The parameterization package used in this study includes a radiation scheme after Ritter and Geleyn (1992), a single-moment bulk microphysics scheme with three ice categories (ice, snow, graupel; see Reinhardt and Seifert 2006), and the surface transfer scheme after Louis (1979). Subgrid-scale turbulent mixing is parameterized by a 3D SmagorinskyLilly closure. This closure is commonly used in large-eddy simulations (LESs) and frequently applied in the cloudmodeling community (e.g., Klemp and Wilhelmson 1978) and has recently been implemented and used with CCLM by Langhans and Schmidli (2012) and Langhans et al. (2012). The schemes for both shallow and deep convection are switched off. Radiation is affected by a subgridscale cloud scheme based on a relative humidity criterion.

The atmospheric part of the system is coupled to the second-generation land surface model TERRA_ML after Heise et al. (2003). Bare soil evaporation is calculated by using a demand-supply approach (BATS; Dickinson 1984) in which the actual evaporation is limited by the maximum rate at which soil moisture can be supplied to the evaporating surface (Desborough et al. 1996). Plant transpiration depends on stomatal resistance which accounts for the biophysical control. It is parameterized following the approach of Jarvis (1976). In CCLM, transpiration is zero below the plant wilting point (at $24 \%$ of soil moisture saturation in our setup) and increases linearly up to the turgor loss point at approximately $60 \%$ saturation in our setup (e.g., Schlemmer et al. 2012). Bare soil evaporation is also zero below the plant wilting point and also reaches its maximum at roughly $60 \%$ saturation but it depends nonlinearly on soil water content. Thus, evapotranspiration is limited by soil moisture for saturation ratios below about $60 \%$ (in our setup).

\section{b. Experimental design}

\section{1) THE DOMAIN}

The model is run in an idealized setup very similar to the framework of Schlemmer et al. (2011). We recall the most important aspects here. The domain spans 440 and $220 \mathrm{~km}$ in the east-west and north-south directions, respectively. The horizontal resolution is $2 \mathrm{~km}$ and the atmosphere is divided into 50 atmospheric layers spread between 20 and $22000 \mathrm{~m}$ above ground. The vertical resolution is enhanced close to the ground with 11 layers concentrated in the first kilometer to better resolve PBL processes. There is no topography and the Coriolis force is neglected. The soil model contains 11 layers of increasing thickness, from $1 \mathrm{~cm}$ at the surface to several meters at $15 \mathrm{~m}$. The first seven of them $(0-1.5 \mathrm{~m})$ are hydrologically active. The homogeneous land surface consists of a loamy soil (porosity of $45 \%$, field capacity and wilting point at $75 \%$ and $25 \%$ of soil moisture saturation, respectively) covered by vegetation (leaf-area index of 2.96 , root depth of $56 \mathrm{~cm}$, and vegetation cover of 0.84 ).

The lateral boundaries are treated by a Davies relaxation (Davies 1976), which relaxes pressure, temperature, water vapor, and wind toward specified reference profiles. These profiles are calculated by averaging over the inner domain and updated every $2 \mathrm{~min}$ in order to maintain a fine equilibrium between the in ner domain and the lateral boundaries. Close to the zones of relaxation, especially along the inflow boundary, precipitation is partly suppressed. The analysis is therefore limited to a subdomain. The so-called "analysis domain" is located $30 \mathrm{~km}$ away of any lateral boundary and $250 \mathrm{~km}$ away of the inflow boundary. We explore the impact of the lateral boundary formulation on the results. To this end, a supplementary simulation is conducted with periodic lateral boundary conditions (detailed later in section 3a).

\section{2) INITIAL CONDITIONS AND RELAXATION}

The initial conditions are introduced using constructed atmospheric profiles of zonal wind, meridional wind, relative humidity, and temperature (see Fig. 1). The atmospheric temperature follows a constant lapse rate of $-6 \mathrm{~K} \mathrm{~km}^{-1}$ up to an altitude of $200 \mathrm{hPa}$. The initial relative soil moisture content is set to $40 \%$ at the surface and increases with depth to reach $100 \%$ at $2.5 \mathrm{~m}$ and 


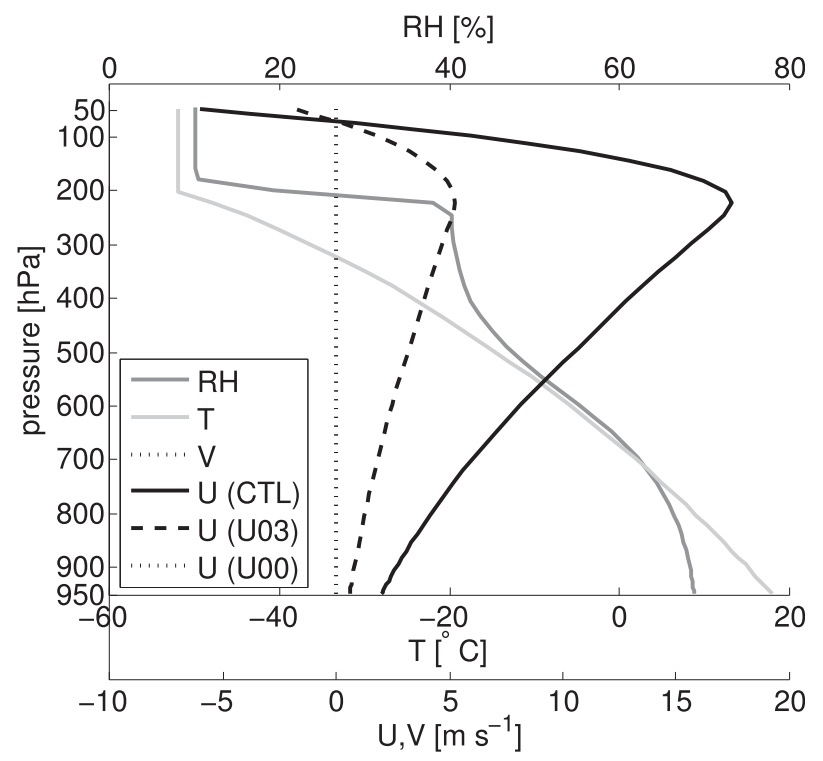

FIG. 1. Atmospheric profiles used for the initialization and relaxation throughout the simulation period. The shown profiles of relative humidity ( $\mathrm{RH}$, dark gray), temperature ( $T$, light gray), and meridional wind ( $V$, dotted black line) are common to all simulations. The westerly zonal wind $(U$, solid, dashed, and dotted black lines) is shown for CTL, U03, and U00. These profiles are associated with midtropospheric velocities of 10,3 , and $0 \mathrm{~m} \mathrm{~s}^{-1}$, respectively. The profiles of $V$ and $U(\mathrm{U} 00)$ are both zero.

below. These profiles resemble typical midlatitude summertime conditions over central Europe (cf. Schlemmer et al. 2011). A saturation of $40 \%$ corresponds to the dry case of Schlemmer et al. (2012). We chose drier soil conditions to generate a regime where evapotranspiration is strongly controlled by water availability. This seems to be a necessary condition for SMP feedbacks to occur (e.g., Koster et al. 2004).

Horizontal inhomogeneity is created at the initialization of the model by adding random perturbations of $\pm 0.02 \mathrm{~K}$ to the temperature of the first atmospheric layer. During the simulations, the model is constantly relaxed toward the initial profiles. The atmosphere is strongly relaxed at high altitudes but runs freely close to the surface (the relaxation time scale is 1 day in the stratosphere, roughly 2 days at $500 \mathrm{hPa}$, and more than 5 days in the PBL). A relaxation of strength increasing with depth is also applied to soil moisture with time scales of 2 days at the deepest layers and more than 10 days at the surface. The relaxation increments are horizontally homogeneous for both the atmosphere and the soil, so that the relaxation procedure has no influence on the horizontal variability. In summary, this numerical design resembles a large and flat midlatitude grassland area in summer under constant synoptic influence which is represented by the atmospheric relaxation. Relaxation of soil water content further ensures that the domain mean surface conditions reach a steady state after several days. Suppressing relaxation would result in a slow drift of the soil conditions and hence of the diurnal equilibrium.

\section{3) EXPERIMENTS}

The wind profile of the standard simulation (CTL) is characterized by vertical shear and an upper-level westerly jet with an amplitude of about $17 \mathrm{~m} \mathrm{~s}^{-1}$. In addition to CTL, two simulations with reduced wind speed (U03 and U00, see Fig. 1) are performed to test the sensitivity of the SMP feedback to the wind profile. We also assess the robustness of the results by running a simulation with double periodic lateral boundaries (PERI) and a simulation with a different formulation of turbulent mixing (NUMDIFF). All experiments are run for a length of 55 days.

\section{Results}

\section{a. The equilibrium state of the simulations}

After around 15 days and in all simulations, the system reaches equilibrium in which deep precipitating convection is triggered every day with little day-to-day variability in terms of timing and magnitude of domainmean precipitation. Mean characteristics of this equilibrium state averaged over the analysis domain and over the last 30 days are summarized in Table 1 . The precipitation rates are small when averaged over the

TABLE 1. Surface and PBL characteristics averaged over the analysis domain and the last 30 days. SWn $=$ net shortwave radiation, $\mathrm{LWn}=$ net longwave radiation, $\mathrm{Rn}=$ net total radiation, $H=$ surface sensible heat flux, $L E=$ surface latent heat flux, $\mathrm{Q} \_0=H+L E$, Tsoil = surface temperature, $\Theta=$ soil moisture saturation ratio over the root depth, and $P=$ precipitation.

\begin{tabular}{lccccccccc}
\hline \hline & $\begin{array}{c}\mathrm{SWn} \\
\left(\mathrm{W} \mathrm{m}^{-2}\right)\end{array}$ & $\begin{array}{c}\mathrm{LWn} \\
\left(\mathrm{W} \mathrm{m}^{-2}\right)\end{array}$ & $\begin{array}{c}\mathrm{Rn} \\
\left(\mathrm{W} \mathrm{m}^{-2}\right)\end{array}$ & $\begin{array}{c}H \\
\left(\mathrm{~W} \mathrm{~m}^{-2}\right)\end{array}$ & $\begin{array}{c}L E \\
\left(\mathrm{~W} \mathrm{~m}^{-2}\right)\end{array}$ & $\begin{array}{c}\mathrm{Q} \_0 \\
\left(\mathrm{~W} \mathrm{~m}^{-2}\right)\end{array}$ & $\begin{array}{c}\text { Tsoil } \\
(\mathrm{K})\end{array}$ & $\begin{array}{c}\Theta \\
(\%)\end{array}$ & $\begin{array}{c}P \\
\left(\mathrm{~mm} \mathrm{day}^{-1}\right)\end{array}$ \\
\hline CTL & 234.1 & -73.9 & 160.2 & 42.4 & 112.2 & 154.6 & 299.4 & 44.0 & 2.26 \\
U03 & 242.2 & -83.4 & 158.8 & 44.1 & 109.6 & 153.7 & 299.5 & 42.4 & 1.85 \\
U00 & 243.6 & -86.0 & 157.6 & 45.8 & 106.0 & 151.8 & 300.2 & 39.9 & 1.56 \\
NUMDIFF & 248.3 & -83.4 & 164.9 & 45.5 & 113.6 & 159.1 & 300.4 & 42.4 & 1.72 \\
PERI & 239.9 & -80.8 & 159.1 & 49.1 & 104.6 & 153.7 & 299.6 & 40.6 & 1.98 \\
\hline
\end{tabular}



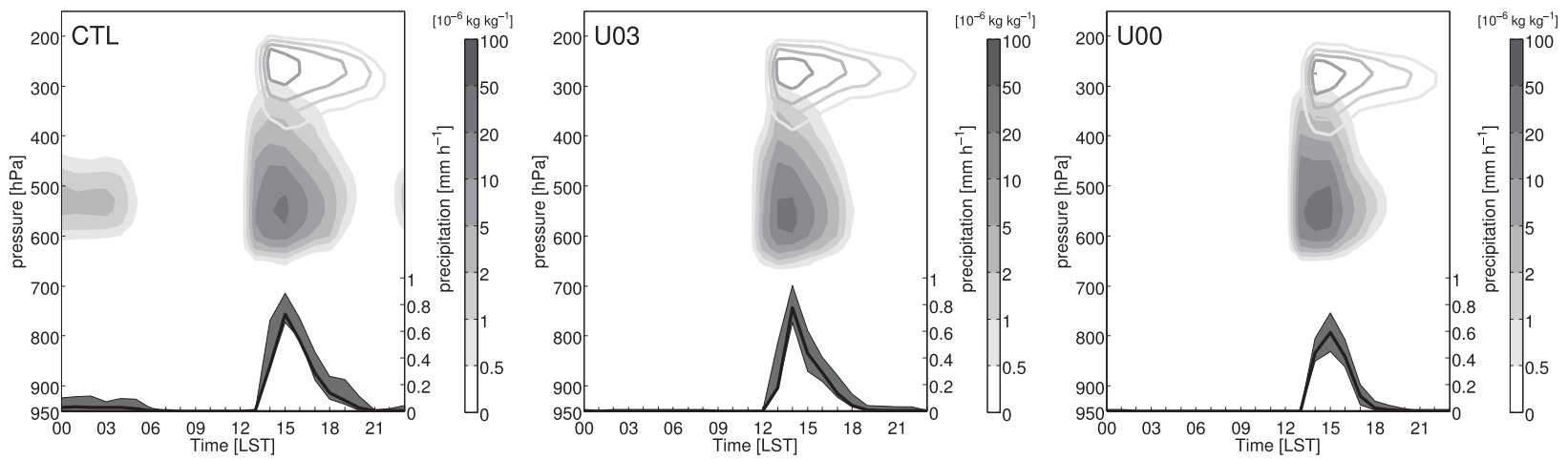

FIG. 2. Average diurnal cycle of convection in (left to right) three simulations with varying background wind profiles (CTL, U03, and U00). Cloud water content ( $\mathrm{kg} \mathrm{kg}^{-1}$, shaded contours), cloud ice content ( $\mathrm{kg} \mathrm{kg}^{-1}$, contour lines), and time series of surface precipitation rate $\left(\mathrm{mm} \mathrm{h}^{-1}\right.$, black solid line) are averaged over the last 30 simulated days and over the analysis domain of $160 \mathrm{~km} \times 160 \mathrm{~km}$. Day-to-day spread of the surface precipitation rate is indicated by dark gray shading.

whole domain, but local rainfall rates reach up to $20 \mathrm{~mm} \mathrm{day}^{-1}$. The different components of the surface energy balance vary little between the different runs but differences in total precipitation vary up to $45 \%$. The simulated decrease of precipitation with decreasing wind speed is due to a change of storm dynamics (discussed later in section 3c) and not to a decrease in evapotranspiration. The reduction of background wind speed from CTL to U00 does not impact surface fluxes because the surface wind is largely independent of the relaxed wind profile (very weak relaxation at near-surface levels, the local flow prevails).

Figure 2 offers insight into the average diurnal cycle during this equilibrium state for CTL, U03, and U00. The three simulations share a common average diurnal cycle in general. The first grid-scale clouds develop at $650 \mathrm{hPa}$ at around $1230 \mathrm{LST}$. They intensify rapidly and extend up to the tropopause and ice is found from $400 \mathrm{hPa}$ upward. These deep clouds are responsible for intense precipitation between 1300 and 1800 LST. Around 2000 LST convection generally ceases. Some differences can nevertheless be found between the simulations. Rain starts usually $1 \mathrm{~h}$ earlier in U03 and stops $1 \mathrm{~h}$ earlier in U03 and U00 compared to CTL.

In CTL some midtropospheric clouds are advected downwind across the domain during the night and can produce some light rain. The midlevel clouds show a minimum at the end of the afternoon and regrow at around 2200 LST. This effect does not occur in U03 and U00 because of the weaker wind profile. We consider these nocturnal clouds as irrelevant for the later discussed SMP feedback since they hardly produce any precipitation (less than $7 \%$ of total precipitation falls between 2200 and 1200 LST) and do not impact the surface energy balance significantly.
The spatial structures that are particularly relevant for this study are investigated later but can be briefly summarized as follows: the cloudy layers in the afternoon consist of deep convective cells. The cores of the cells cover typically $10 \%$ of the domain at 1430 LST and contain up to $3 \mathrm{~g} \mathrm{~kg}^{-1}$ of cloud liquid water. Clouds during the night are more stratiform and show smaller mixing ratios of liquid water. During the afternoon, one can typically find several tens of deep convective cells simultaneously within the whole domain.

\section{b. The soil moisture-precipitation feedback in the CTL simulation}

\section{1) Persistent PRECIPITATION PATteRns}

The spatial distribution of 30 days accumulated precipitation is shown for CTL in Fig. 3a. About eight patches of enhanced precipitation are clearly distinguishable in CTL. They are elongated in the along-wind direction and each patch covers about $300 \mathrm{~km}^{2}$, not much larger than the typical extent of single rainfall events in the model (around $100 \mathrm{~km}^{2}$ ). The accumulated rainfall of $200-250 \mathrm{~mm}$ over such areas originates from a succession of several rain events. Around these zones of intense precipitation, the accumulated rainfall depth often drops dramatically by up to a factor of 4 within a distance of $15 \mathrm{~km}$.

Figure 3a also shows that the zones of enhanced precipitation correspond to areas of wetter soil. The soil moisture saturation (blue contours) is calculated relative to porosity and averaged over the root depth. We denote it hereafter with $\Theta$. It is not astonishing to find a positive correlation between soil moisture and precipitation, since rainfall obviously wets the soil, but a SMP feedback requires that soil moisture influences 

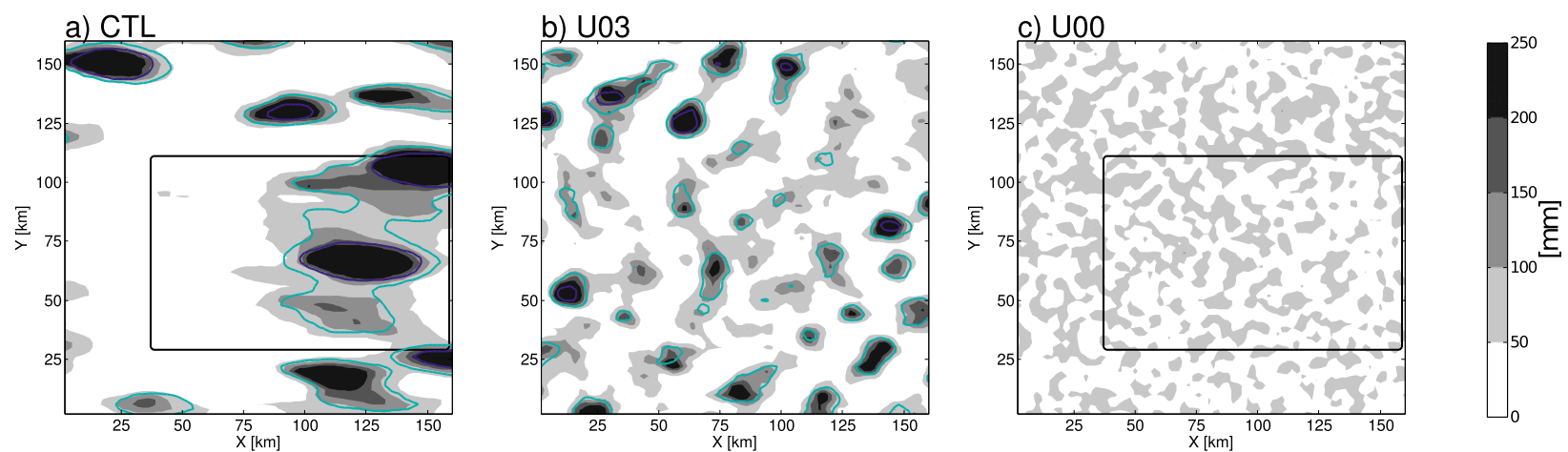

FIG. 3. Spatial distribution of precipitation and soil moisture in the analysis domains of (a) CTL, (b) U03, and (c) U00. Gray shadings indicate total precipitation during the last 30 simulated days $(\mathrm{mm})$ and blue contours indicate soil moisture saturation averaged over the 30 days period (50\% saturation in light blue and $60 \%$ dark blue).

precipitation as well. To show the influence of soil moisture on precipitation, the lagged spatial correlation between soil moisture in the morning and precipitation during the subsequent afternoon is calculated for each day (see Fig. 4). In CTL (solid line) a positive spatial correlation between soil moisture and precipitation evolves within the first simulation weeks. Rain thus preferentially occurs over wetter areas demonstrating a positive SMP feedback. Moreover the correlation increases with time. Enhanced rain over wetter areas intensifies the soil moisture anomalies throughout the simulation which probably enhances the control of soil moisture on precipitation.

\section{2) FROM SOIL MOISTURE TO THE PLANETARY BOUNDARY LAYER}

To understand how soil moisture influences subsequent precipitation, the whole pathway is analyzed step by step. Spatial correlations between $\Theta$ and components of the surface radiation budget, surface fluxes, surface temperature, PBL height, and some convectionrelated parameters are shown for CTL in Fig. 5. Quantitative information (Pearson correlation coefficients and slopes of regression lines) is summarized in Table 2. The relationships are not all perfectly linear but linear regressions are calculated nevertheless and their slopes

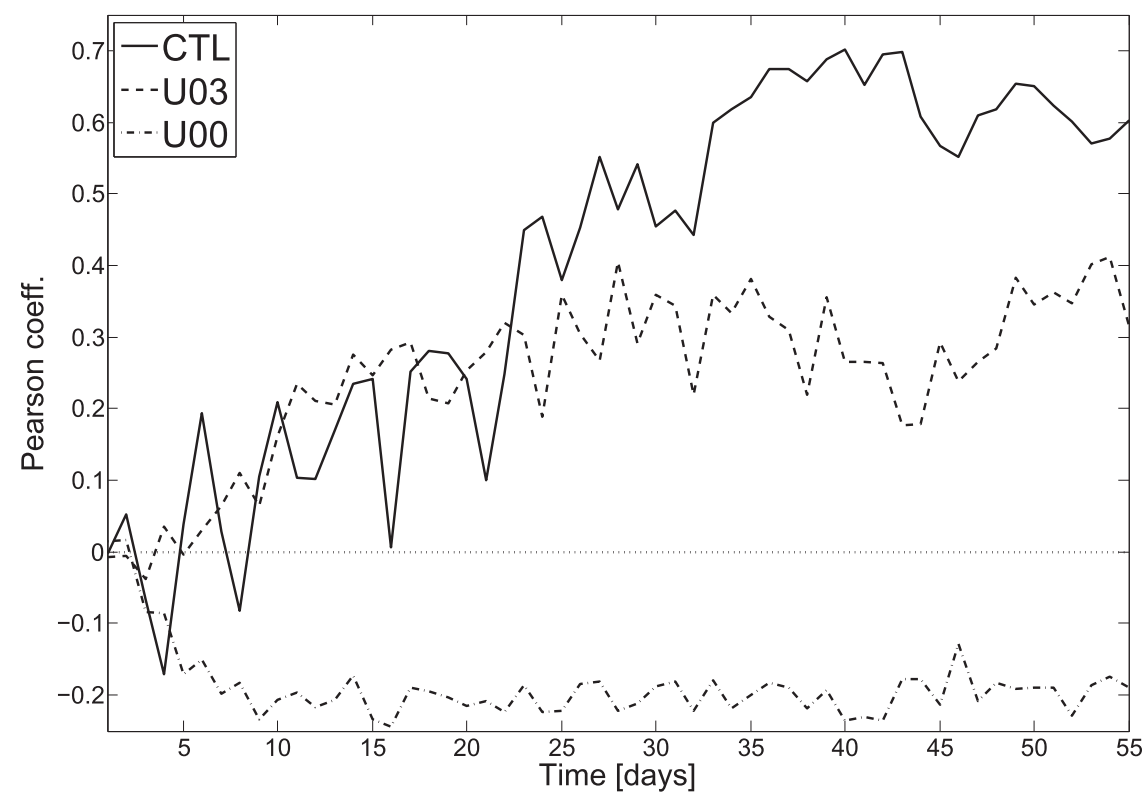

FIG. 4. Spatial correlation (Pearson coefficient) between soil moisture saturation at 0600 LST and precipitation in the afternoon of the same day (1200-2300 LST). All grid points of the analysis domain are included. Daily time series are shown for CTL, U03, and U00. 

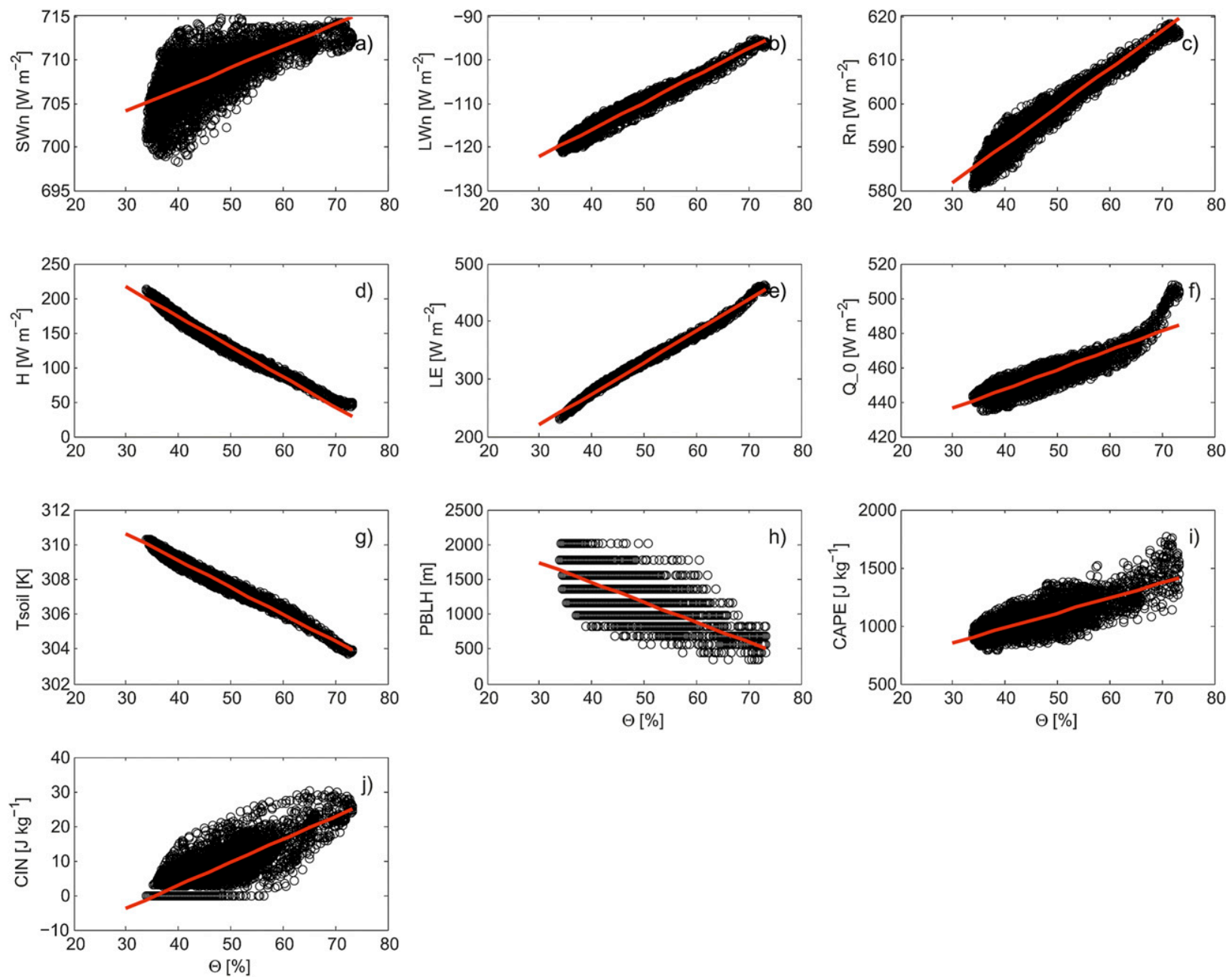

FIG. 5. Spatial relationships between surface or PBL characteristics (vertical axes) and soil moisture saturation (horizontal axes) at 1100 LST on the last day of the CTL simulation. Each dot represents a grid point within the analysis domain (see Fig. 3). Soil moisture saturation $\Theta$ vs (a) surface net shortwave radiation $(\mathrm{SWn})$, (b) surface net longwave radiation $(\mathrm{LWn})$, (c) surface net radiation $(\mathrm{Rn}=$ $\mathrm{SWn}+\mathrm{LWn})$, (d) surface sensible heat flux $H,(\mathrm{e})$ surface latent heat flux $(L E)$, (f) surface total energy flux $\left(\mathrm{Q} \_0=H+L E\right),(\mathrm{g})$ surface temperature (Tsoil), (h) PBL height (PBLH), (i) convective available potential energy (CAPE), and (j) convection inhibition (CIN). Linear regressions (best fit) are indicated by the red lines. Slopes and correlation coefficients are listed in Table 2.

are meant here as rough but comparable estimates of the effect of $\Theta$ on each specific variable. Figure 5a shows a weak increase of the surface net shortwave radiation $(\mathrm{SWn})$ with increasing $\Theta$ together with a higher variability of SWn over drier soils. The net longwave radiative loss (LWn) (Fig. 5b) is reduced at higher $\Theta$. Consequently, the net radiation (Rn) (Fig. 5c) shows a clear dependence on $\Theta$, with wetter areas having a more positive balance (Table 2 indicates a difference of $26.1 \mathrm{~W} \mathrm{~m}^{-2}$ for a $\Theta$ difference of $30 \%$ ). Regarding the surface-to-atmosphere energy fluxes, the flux of sensible heat $H$ (Fig. 5d) is clearly enhanced over drier areas whereas the latent heat flux ( $L E)$ (Fig. 5e) is higher over wetter areas as expected from the surface flux parameterization. The total surface-to-atmosphere energy flux
(Q_0) (Fig. 5f) is less variable, showing that the anomalies in $H$ and $L E$ partly compensate each other but Q_0 nevertheless increases substantially with $\Theta$. The soil temperature at $1-\mathrm{mm}$ depth is $4.5 \mathrm{~K}$ higher at dry spots (Fig. 5g). The PBL height (PBLH, Fig. 5h) is determined by the first level where the vertical gradient of potential temperature exceeds $1 \mathrm{~K} \mathrm{~km}^{-1}$ (e.g., Catalano and Moeng 2010). It is substantially higher over drier areas (increase by $820 \mathrm{~m}$ ). Finally, while the convective available potential energy (CAPE, Fig. 5i) increases with $\Theta$, wetter soils are also associated with higher values of convective inhibition (CIN, Fig. 5j).

The small sensitivity of SWn to $\Theta$ is related to the very small cloud amounts at 1100 LST (no resolved clouds but some subgrid-scale cumuli representing less than 
TABLE 2. Spatial correlations between surface or PBL characteristics and soil moisture saturation $\Theta$ (the first line corresponds to Fig. 5). Each cell of the table contains two values, the Pearson correlation coefficient (top) and the slope of the linear regression line (bottom, units given in header row; expressed as the change associated with an increase of $\Theta$ by $30 \%$ saturation). Example for the first cell: the Pearson correlation coefficient between SWn and $\Theta$ in CTL is 0.70 and SWn increases by $7.5 \mathrm{~W} \mathrm{~m}^{-2}$ with $\Theta$ increasing by $30 \%$ saturation.

\begin{tabular}{lcccccccccc}
\hline \hline & $\begin{array}{c}\mathrm{SWn} \\
\left(\mathrm{W} \mathrm{m}^{-2}\right)\end{array}$ & $\begin{array}{c}\mathrm{LWn} \\
\left(\mathrm{W} \mathrm{m}^{-2}\right)\end{array}$ & $\begin{array}{c}\mathrm{Rn} \\
\left(\mathrm{W} \mathrm{m}^{-2}\right)\end{array}$ & $\begin{array}{c}H \\
\left(\mathrm{~W} \mathrm{~m}^{-2}\right)\end{array}$ & $\begin{array}{c}L E \\
\left(\mathrm{~W} \mathrm{~m}^{-2}\right)\end{array}$ & $\begin{array}{c}\mathrm{Q}_{0} 0 \\
\left(\mathrm{~W} \mathrm{~m}^{-2}\right)\end{array}$ & $\begin{array}{c}\text { Tsoil } \\
(\mathrm{K})\end{array}$ & $\begin{array}{c}\text { PBLH } \\
(\mathrm{m})\end{array}$ & $\begin{array}{c}\text { CAPE } \\
\left(\mathrm{J} \mathrm{kg}^{-1}\right)\end{array}$ & $\begin{array}{c}\mathrm{CIN} \\
\left(\mathrm{J} \mathrm{kg}^{-1}\right)\end{array}$ \\
\hline $\mathrm{CTL}$ & 0.70 & 0.98 & 0.97 & -0.99 & 1.00 & 0.92 & -0.99 & -0.68 & 0.81 & 0.85 \\
& 7.5 & 18.6 & 26.1 & -130.2 & 163.8 & 33.9 & -4.5 & -819.9 & 386.4 & 19.8 \\
U03 & 0.41 & 0.62 & 0.71 & -0.98 & 0.99 & 0.69 & -0.98 & -0.69 & -0.39 & 0.66 \\
& 16.5 & 10.2 & 26.7 & -130.5 & 162.0 & 31.2 & -4.5 & -1048.3 & -215.7 & 4.5 \\
U0 & 0.02 & 0.21 & 0.13 & -0.87 & 0.88 & 0.12 & -0.84 & -0.11 & -0.32 & 0.21 \\
& 4.5 & 13.8 & 18.3 & -162.3 & 178.8 & 16.8 & -5.1 & -582.2 & -451.2 & 2.1 \\
NUMDIFF & 0.82 & 0.94 & 0.98 & -0.98 & 0.99 & 0.88 & -0.98 & -0.62 & 0.31 & 0.70 \\
& 4.5 & 19.5 & 24 & -133.2 & 163.2 & 30 & -5.1 & -852.2 & 232.8 & 11.7 \\
PERI & 0.31 & 0.90 & 0.84 & -0.98 & 0.99 & 0.83 & -0.99 & -0.77 & 0.5 & 0.81 \\
& 7.2 & 17.4 & 24.6 & -142.8 & 168.6 & 25.8 & -4.5 & -900.8 & 192.9 & 20.1 \\
\hline
\end{tabular}

$10 \%$ cloud fraction). This contrasts with some previous studies (e.g., Betts and Viterbo 2005; Betts et al. 2013) who observed cloud-induced variations in SWn by up to several hundreds of watts per square meter. These studies are not necessarily in conflict with our results as Betts and colleagues assessed daily mean radiation data while our study looks at instantaneous data at 1100 LST, that is, at a time before cloud formation becomes significant in our simulations. The comparison with Betts and colleagues, however, shows that the presence of clouds would lead to significant changes. Schlemmer et al. (2012) performed simulations with a similar setup but with $60 \%$ and $80 \%$ initial soil moisture saturation. In such simulations, shallow clouds develop in the morning and induce substantial variations in SWn. Also the daily mean equivalent of Fig. 5 (not shown) is dominated by the presence of deep clouds in the afternoon and resembles closely observations from Betts and Viterbo (2005). The clear-sky morning energy budget considered here is nevertheless particularly relevant since it represents the time when local circulations and instability are build up in association with $\Theta$ anomalies.

The net LW loss is reduced over the wet soil due to the combined effects of lower outgoing emissions (lower soil temperature) and, more importantly, increased downward emissions associated with a more humid PBL (increased emissivity). Combining the results from Fig. 5 and Table 2 shows that from the $26.1 \mathrm{~W} \mathrm{~m}^{-2}$ increase of net radiation from dry to wet areas, $18.6 \mathrm{~W} \mathrm{~m}^{-2}$ can be attributed to a reduced $\mathrm{LW}$ loss and $7.5 \mathrm{~W} \mathrm{~m}^{-2}$ to a higher SW absorption (decrease of the sparse subgridscale cloud cover and decrease of albedo). Table 2 shows that $33.9 \mathrm{~W} \mathrm{~m}^{-2}$ more energy is transferred to the atmosphere over wet soils. Three-quarters $\left(26.1 \mathrm{~W} \mathrm{~m}^{-2}\right)$ can be linked to a surplus in the surface radiation balance, whereas the rest has to come from differences in ground heat flux (the ground heat flux is not directly analyzed but evidence for its lower intensity over wet areas is provided by the substantially lower soil temperature). The higher PBL height over drier areas is a direct consequence of the more buoyant surface parcels associated with a stronger $H$. Initiation of deep convection appears more likely over drier areas because of lower CIN, but on the other hand, stronger storms and more intense precipitation are expected over wetter areas because of larger CAPE. Atmospheric profiles over dry and wet areas are very similar outside of the PBL and reasons for the $\Theta$ dependency of CAPE and CIN must stem from the lower levels. Lifting condensation level (LCL) and level of free convection (LFC) are very close in our setup so that the amount of CIN (energy needed to reach the LFC) is determined mostly by dry convection and is therefore lower over drier soils where air parcels have a higher dry static energy (here $C_{p} T$, where $C_{p}=$ $1005 \mathrm{~J} \mathrm{~K}^{-1} \mathrm{~kg}^{-1}$ is the specific heat of air). CAPE, on the other hand is an index for energy available in case of deep convection (from LFC upward) where ascending parcels are typically saturated and experience moist adiabatic lifting. It follows that CAPE is mostly dependent on the moist static energy (MSE) of surface air which is, unlike $C_{p} T$, higher over wet soils. Higher values of Q_0 can be one reason for the increased MSE over wet soils, but is it the only one?

To answer this question the profiles of the differences in temperature $(\delta T)$, specific humidity $\left(\delta Q_{v}\right)$, and MSE $(\delta \mathrm{MSE})$ between wet and dry patches are investigated in Fig. 6 . The average profile over the $10 \%$ driest areas is subtracted from the average profile over the $10 \%$ wettest areas. The profiles are all converted into kilojoules per kilogram based upon the following MSE equation along a horizontal model layer:

$$
\delta \mathrm{MSE}=C_{p} \delta T+L_{v} \delta Q_{v},
$$




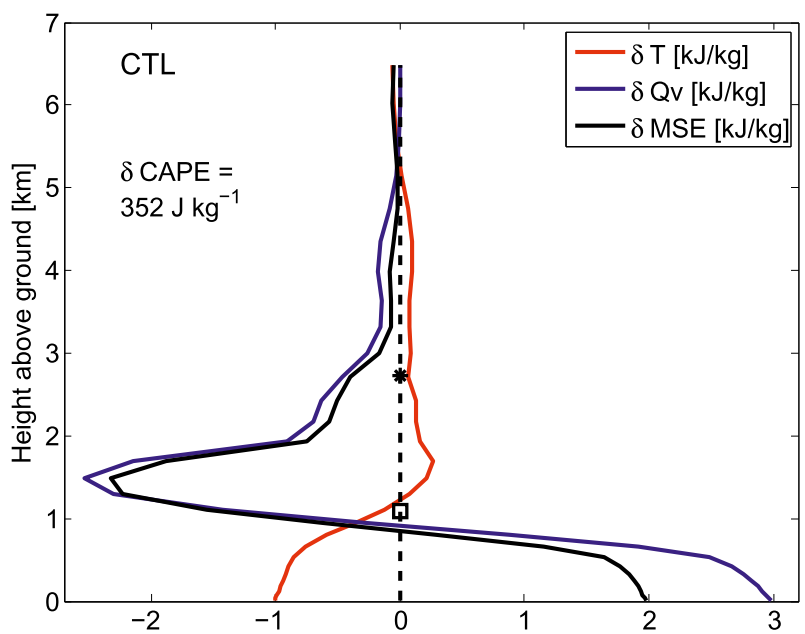

FIG. 6. Horizontally averaged differences in temperature $(\delta T)$, specific humidity $\left(\delta Q_{v}\right)$, and moist static energy ( $\left.\delta \mathrm{MSE}\right)$ between the $10 \%$ wettest and the $10 \%$ driest areas of the domain (wet minus dry) at 1100 LST on the last day of the CTL simulation. The differences are converted to energy units for comparison. A square (asterisk) marks the averaged PBL top of the wet (dry) areas.

with the latent heat of vaporization $L_{v}=2.6 \times 10^{6} \mathrm{~J} \mathrm{~kg}^{-1}$, the temperature increment $\delta T(\mathrm{~K})$ and the specific humidity increment $\delta Q_{v}$. A square (asterisk) marks the average PBL top over wet (dry) portions of the soil. In the lowest $1 \mathrm{~km}$ of the atmosphere $Q_{v}$ is higher over wet soils as expected but this difference becomes reversed from 1 to $3 \mathrm{~km}$ above ground. Temperature variations $\delta T$ show an inverse behavior compared to $\delta Q_{v}$ but with a remarkably smaller amplitude in energy units, so that $\delta \mathrm{MSE}$ is mostly driven by $\delta Q_{v}$. We also notice that all differences change in sign at the altitude of the wet areas PBL top. In particular, above $1 \mathrm{~km}$ the air is substantially dryer over wet patches, as a stable layer decouples that level from near-surface conditions. In summary, while over wet areas the shallow PBL concentrates the surface energy fluxes in the lowest atmosphere, those are more diluted over dry areas because of the deeper mixed layer. Enhanced surface MSE over wet areas due to a shallower mixing depth has already been described by Schär et al. (1999). It explains why CAPE is substantially higher over wet areas while Q_0 is only slightly enhanced.

The statistical relations discussed above are consistent with observational studies, although in reality the signal is noisier. Similar relationships between soil moisture and surface temperature, PBL height or the partitioning of $H$ and $L E$, as well as between PBL height and CIN, CAPE, or MSE have been observed during field campaigns like the Convective and Orographically-Induced Precipitation Study (COPS; Barthlott and Kalthoff 2011; Kalthoff et al. 2011) or the African Monsoon Multidisciplinary Analysis (AMMA; Taylor et al. 2007).
The following contrasting conclusion arise from surface energy considerations: while high CAPE would strengthen convective rainfall over wet areas, low CIN would favor convection initiation over dry areas. No clear explanation for the simulated positive SMP feedback can be drawn yet and a detailed spatial analysis of the convective cycle is thus performed in the next section.

\section{3) FROM CONVECTION INITIATION TO RAINFALL: A SPATIAL ANALYSIS}

We now focus on one particular day and one particular area of the domain to investigate the spatial distribution of convective structures and their role in the SMP feedback. For that purpose, a subdomain of the CTL simulation with strong soil moisture gradients has been selected (see Fig. 7a). Figure 7a shows $\Theta$ in gray shadings, PBL updrafts in green, deep convective cells in blue, and areas of intense afternoon rainfall in red. The westerly wind comes from the left. A wet soil anomaly centered around $x=80, y=40 \mathrm{~km}$ and elongated in the $x$ direction is surrounded by other wet patches and drier surfaces in between. The zones of PBL ascent are found over dry areas, close to the steepest soil moisture gradients and preferentially around the upwind half of wet soil patches. Deep convective cells are almost exclusively triggered upwind of the wet patches. Rain is mostly located over the wet patches as expected by the positive soil moisture-precipitation correlation in Fig. 4. The solid line in $y=40 \mathrm{~km}$ corresponds to a vertical cross section shown in Fig. 8. In Fig. 8a vertical wind is shown in green and anomalies of horizontal wind in black. CIN, CAPE, and $\Theta$ are plotted below the panel. We notice that the PBL updraft (solid green contour) is part of a local circulation extending from the surface up to 2-km height. The circulation includes a compensating downdraft area over the wet patch, horizontal convergence below the updraft, and horizontal divergence above. Figure $8 \mathrm{~b}$ is similar to Fig. $8 \mathrm{a}$ but shows temperature anomalies in red, PBL top in cyan, and isentropes of potential temperature at $0.2-\mathrm{K}$ interval in black. From Fig. $8 \mathrm{~b}$ we notice that the wind circulation is linked with a warmer and deeper PBL over the dry part. The absence of vertical potential temperature gradients indicates a well-mixed PBL.

While the preferred location of PBL updrafts and convection initiation over dry soils and close to soil moisture gradients has been reported in numerous studies, their preferential occurrence upstream of wet patches has rarely been observed. Recent observational evidence is nevertheless provided by Taylor et al. (2011b) who found that convection is initiated preferentially upstream of wet patches by relating soil moisture gradients with the initiation of thousands of MCS over the Sahel 

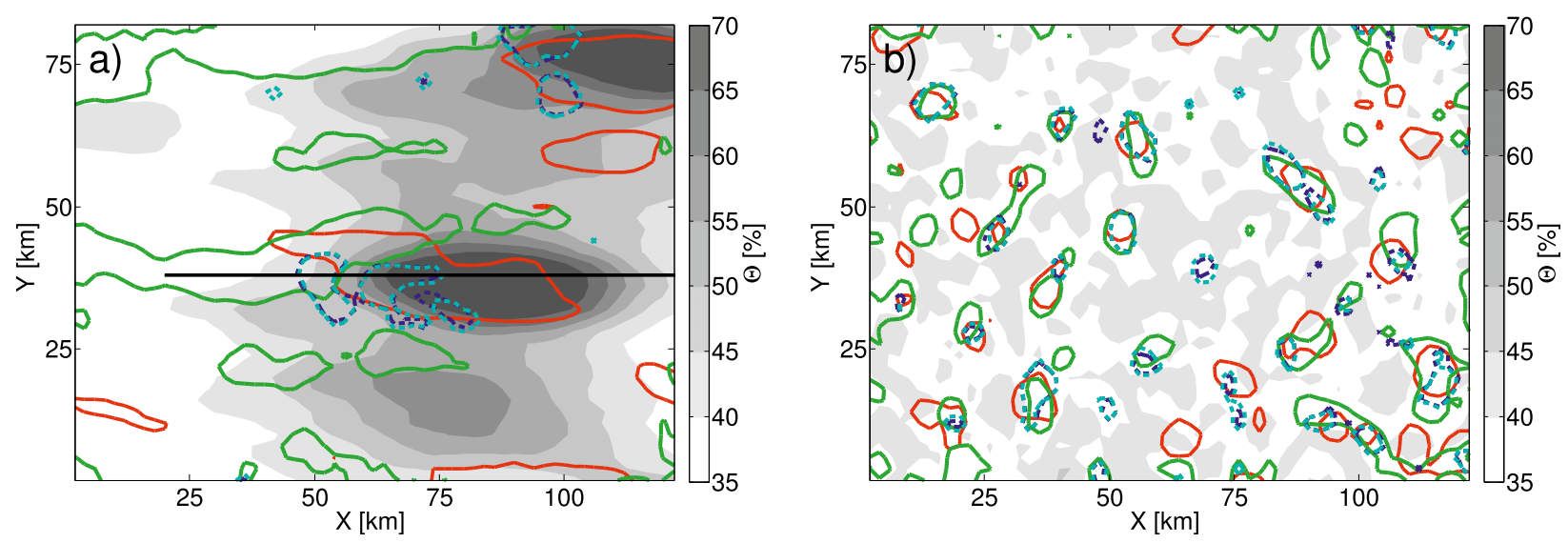

FIG. 7. Horizontal view of convection-related structures during the last simulated day of (a) CTL and (b) U00. The subdomains shown here correspond to the black rectangles in Fig. 3. The soil moisture saturation $\Theta$ at 1100 LST is depicted by gray shadings while a solid red line delimits areas with more than $5 \mathrm{~mm}$ of afternoon precipitation (1100-1800 LST) and a solid green line delimits areas of ascending PBL air at $1100 \mathrm{LST}$, (average grid scale vertical velocity between 150 and $1000 \mathrm{~m}>2 \mathrm{~cm} \mathrm{~s}^{-1}$ ). Deep convective cells are delimited between 3000 and $4500 \mathrm{~m}$ at 1330 LST by vertical ascent $>1 \mathrm{~m} \mathrm{~s}^{-1}$ (blue dashed contour) and cloud liquid water content $>2^{-4} \mathrm{~kg} \mathrm{~kg}^{-1}$ (cyan dashed contour). The vertical velocity field has been slightly filtered for display purposes.

region. They concluded that the surface-induced local circulations are stronger when the shallow horizontal flow is opposite to the background wind. Adler et al. (2011) also discussed convection initiation over dry areas and upstream of wet areas in simulations of MCS over the Sahel. Possible reasons for the asymmetry of the strength of the local circulations (apparently not equally strong over equally steep soil moisture gradients all around a wet patch) are discussed later in section 4 .

The deep convective cells are also located over the upwind part of wet patches but they are shifted some 20$25 \mathrm{~km}$ to the right, as the cells propagate downwind. These deep convective cells typically continue to propagate during the afternoon and evolve into storms (here we call storms precipitating convective systems that stay active for several hours). They produce precipitation farther downwind where a wet soil is likely to be found, therefore the positive SMP feedback. A detailed look at animations of the simulations (not shown) indicates that storms often propagate farther than the wet patches and pass over successive wetter and drier areas. Rain can thus, in principle, also fall over dry areas, but the storms tend to produce systematically more precipitation when passing over wet areas. Both CIN and CAPE are higher over wet areas, but in case of a propagating storm, surface lifting is not an issue since
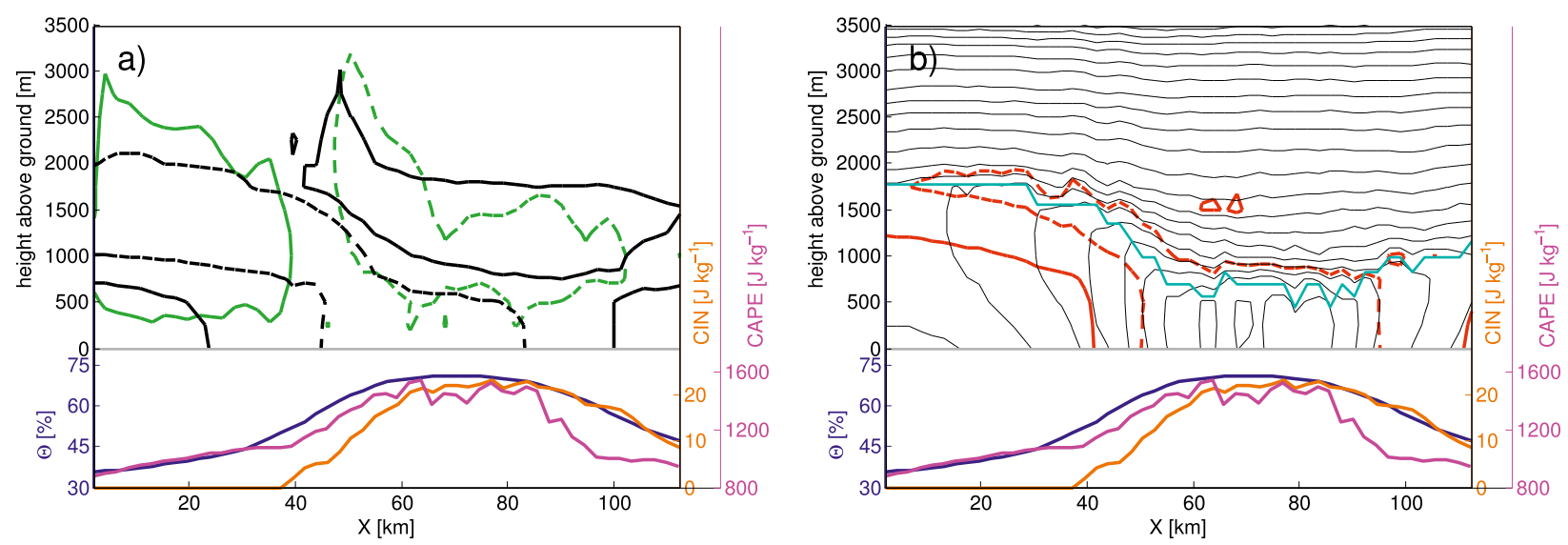

FIG. 8. Vertical cross sections of (a) PBL circulation and (b) PBL structure taken along the black line in Fig. 7a at 1100 LST. The soil moisture saturation $\Theta$ (blue), CIN (orange), and CAPE (magenta) are displayed in the lower part of the panels. (a) Vertical wind is shown in green with a dashed contour at $-4 \mathrm{~cm} \mathrm{~s}^{-1}$ and a solid contour at $+4 \mathrm{~cm} \mathrm{~s}^{-1}$ and anomalies of horizontal wind (deviation from the crosssection layer mean) are shown in black with a dashed contour at $-0.4 \mathrm{~m} \mathrm{~s}^{-1}$ and a solid contour at $+0.4 \mathrm{~m} \mathrm{~s}^{-1}$. (b) The structure of the boundary layer is depicted by black potential temperature contours at a $0.2 \mathrm{~K}$ interval. In addition, temperatures anomalies are shown in red with a dashed contour at $-0.2 \mathrm{~K}$ and a solid contour at $+0.2 \mathrm{~K}$ and the PBL top is marked in cyan. 
the precipitation-induced cold pool is typically sufficient to overcome any CIN and force surface parcels to rise up to their LFC.

Hence, while convection initiation is favored over dry areas, background advection and higher values of CAPE lead to enhanced rain over wet areas. These results are consistent with previous studies like Taylor et al. (2010) and Gantner and Kalthoff (2010) who also found that convection initiation is favored over dry areas and close to strong soil moisture gradients and that convection in mature convective systems becomes more (less) intense when passing over areas with a wetter (drier) surface.

\section{c. The role of the background wind}

Since the propagation of deep convective cells turned out to be relevant for the SMP feedback, the sensitivity to the background wind is further analyzed here by running U03 and U00, two simulations where the reference wind profile is reduced by a factor of 3 and set to zero, respectively.

Similar to CTL, U03 exhibits a rather heterogeneous precipitation distribution (see Fig. 3), and an overlap of isolated areas of enhanced precipitation with wet soil anomalies is noticeable. The zones of enhanced precipitation are, however, less elongated in along-flow direction than in CTL. The correlation between soil moisture and precipitation in Fig. 4 evolves similar to CTL but stabilizes around 0.3 instead of 0.6 , meaning that a weaker but still positive SMP feedback is generated in U03.

In U00, however, the differences relative to CTL are more significant. Accumulated precipitation in Fig. 3 is more homogeneously distributed and appears not to be correlated with soil moisture anomalies. The values of $\Theta$ are all contained in a $10 \%$ moisture saturation difference and rainfall depths amount mostly between 30 and $90 \mathrm{~mm}$. In addition, the correlations for U00 in Fig. 4 exhibit a negative SMP feedback, with values around -0.2 during the whole simulation. A negative SMP feedback implies continuous damping of soil moisture anomalies which stay thence weak and of relatively low influence for the development of convection. Figure $7 b$ is similar to Fig. 7a but for simulation U00. PBL ascent is located over dry soils like in CTL but here the convective structures evolve and precipitate in the vicinity of their preceding PBL updrafts. If there is no background wind supporting the propagation or advection of convective cells in our setup, the whole convective cycle is almost fixed to the location of convection initiation and a negative SMP feedback is generated. The works of Emori (1998) and Avissar and Liu (1996) present significant similarities with the U00 case. They reported a strongly negative SMP feedback with weak background winds (but did not investigate the corresponding strongerwind cases). Indeed, in their simulations, like in U00, the rain falls at the location of convection initiation. The role of the background wind in breaking down the initially negative local SMP feedback still needs to be demonstrated in observations. As a step in that direction, Chagnon et al. (2004) found that preferential occurrence of early afternoon cumuli over deforested areas can be reduced by a higher wind speed.

Our results suggest that there is a critical wind necessary for the negative SMP feedback to turn positive. This wind is low in our setup (approximately half of U03) and is likely to be dependent on the environmental conditions. Based on the underlying mechanisms disentangled here, one might for example expect this critical wind to scale with the size of the soil moisture anomalies (distance to travel from convection initiation to the next wet patch).

Table 1 also shows that area-mean precipitation decreases significantly with decreasing background wind, although evaporation remains almost constant. The fact that the storms hardly reach the areas of high CAPE in U00 might explain part of the decrease in precipitation. Differences in storm dynamics (smaller, less organized, more stationary, and shorter-lived storms in U00) or moisture advection from the upstream domain in CTL and U03 are probably also important. The impact of wind on the development of convection over large areas has already been recognized by Findell and Eltahir (2003b). They found that while low wind can enhance convection, strong shear tends to suppress it.

\section{d. Quantitative assessment of the SMP feedback}

Figures 9a-c show 30-day averages of depth, probability, and intensity of precipitation as functions of $\Theta$. The three experiments with varying wind profiles (CTL, U03, and U00) are compared. The associated statistical distributions of $\Theta$ are shown by probability density functions (PDFs) in Fig. 9d. In CTL and U03 the 10\% wettest areas get typically at least $4-\mathrm{mm}$ precipitation per afternoon while the $10 \%$ driest areas experience less than $1 \mathrm{~mm}$. Precipitation probability and intensity are clearly enhanced over wet patches (positive feedback), and PDFs of $\Theta$ are wide and positively skewed. In U00 on the other hand, relatively dry areas receive on average more than $2 \mathrm{~mm}$ of rain per afternoon, while less than $1 \mathrm{~mm}$ falls over the relatively wet regions. Both the precipitation intensity and probability are clearly enhanced over dry soil (negative feedback), and the soil moisture saturation stays relatively homogeneous during the simulation (narrow PDF) with almost all grid points contained in a saturation range between $36 \%$ and $44 \%$.

The homogeneous soil moisture distribution in U00 is a direct consequence of continuous damping of the soil 

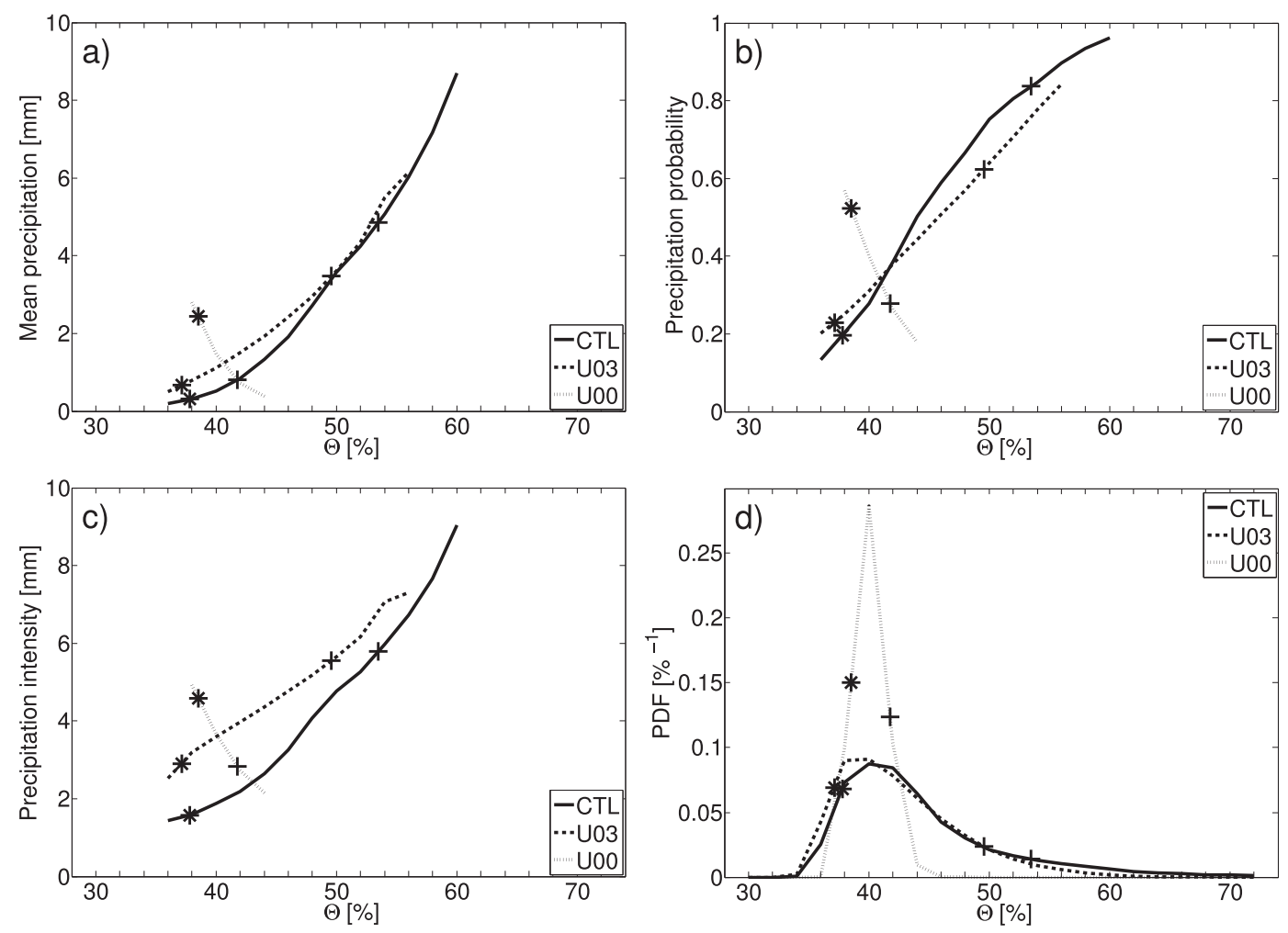

FIG. 9. Spatial analysis of afternoon precipitation (1200-2300 LST) as a function of soil moisture saturation $\Theta$ in the morning (0600 LST): (a) mean precipitation, (b) probability of afternoon precipitation $\geq 0.1 \mathrm{~mm}$, (c) intensity of precipitation given afternoon precipitation $\geq 0.1 \mathrm{~mm}$, and (d) PDFs of $\Theta$. All grid points of the analysis domain at each of the last 30 days are included. For each simulation, the 10th and 90th percentiles of $\Theta$ are shown with an asterisk and a cross, respectively. In (a)-(c), each $\Theta$ class ( $2 \%$ bin width) contains at least 2000 grid points ( $1 \%$ of total).

moisture anomalies, while in the other cases preferential rain over wet soil intensifies the moisture anomalies leading to wider PDFs. The positive skewness of the PDFs further depicts the presence of small areas of very wet soil surrounded by larger areas of rather dry soil and illustrates the persistent, localized, and spotty character of precipitation in this setup.

The simulated positive SMP feedbacks result both from increased frequency and increased intensity of precipitation over wetter areas. Findell et al. (2011) analyzed the dependency of afternoon precipitation upon the morning evaporative fraction $\mathrm{EF}=L E /(H+L E)$ in gridpoint time series of the North American Regional Reanalysis dataset ( 25 summers, $30-\mathrm{km}$ grid). They concluded for the wetter regions investigated (the ones closest to our setup with EF around 0.7) that precipitation frequency increases dramatically with EF while intensity stays relatively constant. This contrasts with our results. Note that the straightforward dependency of EF on $\Theta$ in our setup implies that using EF instead of $\Theta$ as precipitation predictor would lead to unchanged conclusions. The contrasting results are not necessarily contradictory, because of the fundamental differences between the spatial scales considered (grid spacing of $30 \mathrm{~km}$ in Findell et al. and $2 \mathrm{~km}$ in the current study). While the $2-\mathrm{km}$ resolution resolves developing convection along local soil moisture gradients, the $30-\mathrm{km}$-resolution reanalysis data consider temporal variations of the regionally averaged soil moisture content. Findell et al. investigate temporal soil moisture variations while we model spatial soil moisture variations. This has many implications. For example, while one can expect that most of the processes involved in the clear-sky energy budget hold for spatial and temporal variations, this is likely not the case for processes affected by cloud formation. Clouds are preferentially initiated over drier soil in the spatial case but can be positively correlated with wet soil conditions in temporal variations (Betts and Viterbo 2005; Findell and Eltahir 2003a). Also the role played by the background wind is fundamentally different. In our study, the displacement of cumulus from dry to wet soil patches is the key mechanism, while the general suppression or general enhancement of convection (regardless of soil moisture gradients) is relevant if 

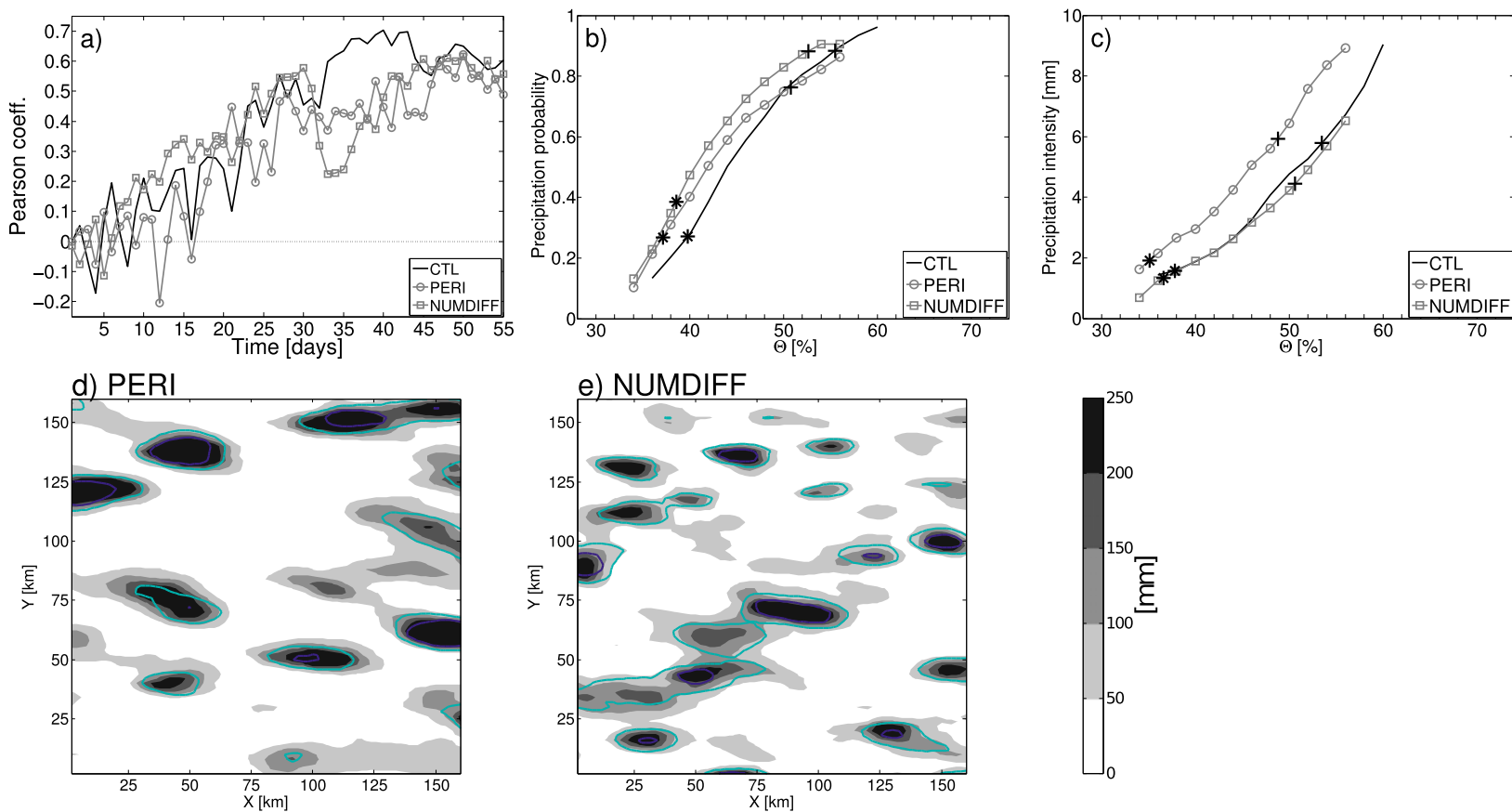

\section{e) NUMDIFF}
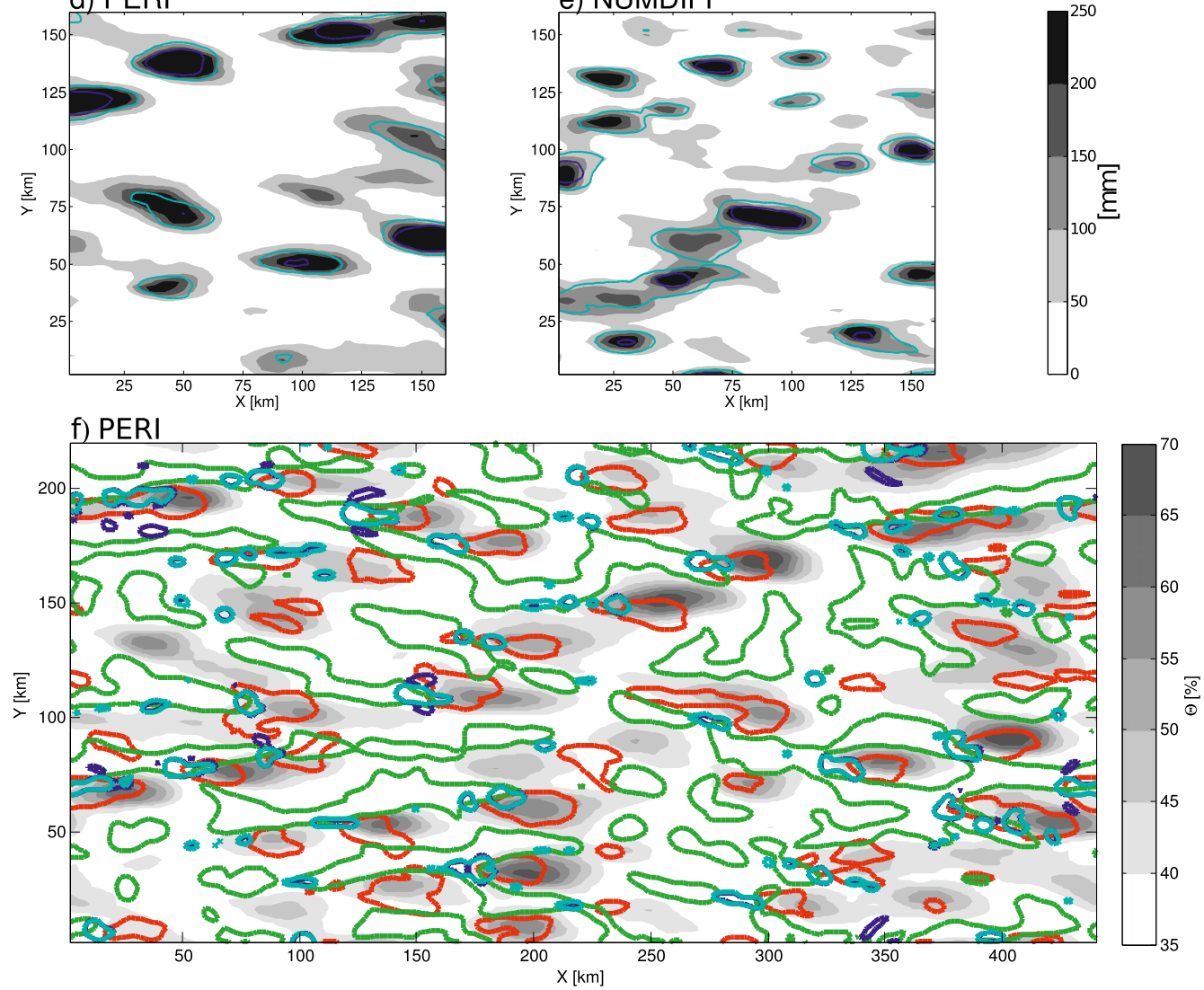

FIG. 10. Summary of numerical sensitivity studies. (a) As in Fig. 4, but for CTL, PERI, and NUMDIFF. (b), (c) As in Fig. $9 \mathrm{~b}$ and $9 \mathrm{c}$, but for CTL, PERI, and NUMDIFF. (d),(e) As in Fig. 3, but for PERI and NUMDIFF. (f) As in Fig. 7, but for PERI and for the whole computational domain.

temporal variations over large domains are considered (Findell and Eltahir 2003b).

\section{e. Numerical sensitivities}

\section{1) TreatMent of THE LATERAL BOUNDARIES}

A run similar to CTL but with double-periodic lateral boundaries (PERI) is performed to ensure that the simulated feedbacks are not influenced by the lateral boundary conditions. Comparing CTL against PERI in Figs. 10a-c indicate a very similar feedback strength in both simulations. Also regarding the spatial structures in Fig. 10d, the islands of high precipitation depth and wet soil in PERI are very similar in size, amplitude, and shape as the ones in CTL (shown before in Fig. 3a). They are however distributed more randomly in the alongflow direction (CTL presents an increased density of wet patches from $x=100 \mathrm{~km}$ eastward). Hence, while the feedback sign and strength as well as precipitation variability at scales up to $\sim(20-30) \mathrm{km}$ are largely unaffected by the boundary formulation, the preferential occurrence of precipitation downstream of the domain in CTL is linked to the numerical setup. In CTL, the first rain is found some $150 \mathrm{~km}$ downstream of the inflow 
boundary because of the time required to generate convective cells and produce precipitation. Because subsequent cells develop on soil moisture anomalies created by previous ones, an $x$ dependency of the results can persist farther downstream. This phenomenon applies to all simulations with relaxed lateral boundaries but is most apparent in CTL.

Periodic lateral boundaries also, on the other hand, offer the possibility to extend the analysis to the whole computational domain and to represent more convective structures simultaneously (see Fig. 10f). Comparing Figs. 10f and 7a reveals that the key features of the simulated feedbacks in PERI and CTL are identical (note the different scale between both plots). In both cases, the PBL updrafts are located over drier soils, close to and preferentially upstream of wet patches. Deep convective cells are initiated just upstream of the wet patches and heavy rainfall occurs mainly over the wet patches.

Relaxed rather than periodic lateral boundary conditions were chosen as default because resonance effects affected the rainfall distribution in some of the periodic runs (with initial soil moisture amounting to at least $60 \%$ ). In these cases the size of the computational domain in conjunction with the diurnal forcing did affect the distribution of wet and dry patches, and the potentially long lifetime of convective systems favored squall lines that propagated once across the domain per day. It turned out that this resonance process produces soil moisture variability at scales that are larger than the ones in CTL, while similar conclusions emerged regarding the SMP feedback. There might be no perfect treatment of the lateral boundaries for our idealized study but the fact that the SMP feedback is overall very similar in the two different setups provides confidence that the results are robust.

\section{2) TURbUlENCE FORMULATION}

A second critical aspect of the experiment is linked to the comparatively low spatial resolution of our simulations. Indeed, whereas turbulence schemes from mesoscale models are only applicable when the grid size is substantially larger than the largest turbulence scale, and LES schemes assume that the energy-containing turbulence scales are resolved, none of these assumptions can be strictly fulfilled by cloud-resolving models in the "terra incognita" range (Wyngaard 2004). The sensitivity to the turbulence formulation is thus tested by running the NUMDIFF simulation. NUMDIFF is similar to CTL but the LES-based turbulence scheme is replaced by a 1.5-order turbulent kinetic energy-based 1D PBL scheme (see Raschendorfer 2001) of level 2.5 in the Mellor and Yamada notation (Mellor and Yamada 1974), coupled with a monotonic fourth-order numerical filter in the horizontal.

The amplitude and strength of the SMP feedback is remarkably similar between CTL and NUMDIFF in Figs. 10a-c. The wet soil patches in Fig. 10e are of similar magnitude and shape as the ones in CTL, but somewhat less extended and more numerous. Deep convective cells are also more numerous and less extended (not shown). Interestingly, a diagonal arrangement of wet patches can be seen starting from the lower left corner. Diagonal arrangements of wet patches are present in all simulations but seem slightly more frequent in NUMDIFF. They might be related to storm splitting events which are found for a minority of storms. An example of storm splitting can be seen in Fig. 10f $(x=160$, $y=120 \mathrm{~km}$ ). Precipitation splits the updraft and leads to a left- and a right-moving convective cell. Analyzing in detail the impact of the turbulence formulations on the storm dynamics is beyond the scope of this study, but the presence of more numerous and less extended deep convective cells (rain patches) in NUMDIFF might be related to a reduced horizontal PBL mixing. While the size of convective cells is sensitive to the turbulence formulation, the SMP feedback remains largely unchanged, which again highlights the robustness of the findings regarding the numerical setup.

\section{Discussion}

Two major mechanisms have been isolated that are responsible for the simulated SMP feedbacks. They are discussed here with conceptual vertical along-flow cross sections in Figs. 11 and 12.

Figure 11 depicts the initiation of convection. Local thermal circulations develop along soil moisture gradients with ascending motions over drier areas. The associated zones of PBL ascent help to overcome convective inhibition (CIN) and favor the development of shallow and deep cumulus over dry patches. In the case of no background wind (Fig. 11, left), the deep convective cells remain stationary. The whole convective cycle takes place at the location of initiation and rain falls over the dry soil. The presence of unidirectional wind (Fig. 11, right) decisively influences the mechanism chain in two steps.

First, the background wind favors the local circulation upwind of the wet patch and slows down the one downwind. This simulated phenomenon is corroborated by some observational studies (e.g., Taylor et al. 2011b) but lacks to our knowledge an explanation. We hypothesize that the nonzero horizontal vorticity term of low-level wind (increase of velocity with height) might play a role in this case. Upwind of the wet patch, the 

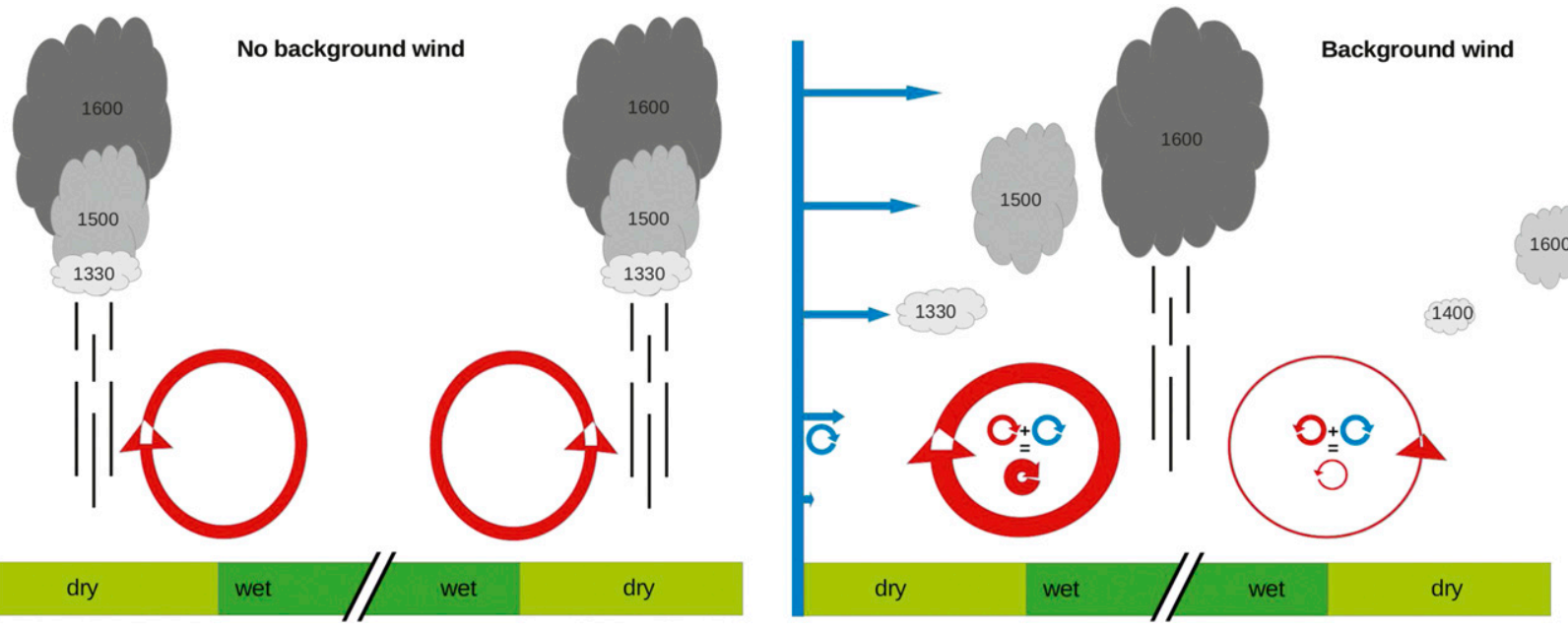

FIG. 11. Conceptual scheme of convection initiation over soil moisture gradients. (left) Without background wind, convection is initiated over the dry areas and over the ascending branches of local sea-breeze-like circulations in the planetary boundary layer (red circular arrows). Storms are stationary and rain falls predominantly over the dry areas. The numbers in the clouds indicate LST. (right) With significant background wind (blue arrows), the superposition of the local and the background vorticity terms (small red and blue circular arrows, respectively), enhances (weakens) the circulation upstream (downstream) of the wet patch. Convection is preferentially initiated upstream of the wet patch, developing storms are propagating downwind, and rain falls preferentially over the wet patch.

PBL vorticity has the same sign as the vorticity associated with the thermally driven circulation (constructive superposition), while the two contributions have opposite signs downwind. The addition of both local and mesoscale vorticity terms enhances (weakens) the upwind (downwind) thermal circulation and consequently favors the development of deep convective cells on the upwind side of the wet soil anomalies.
The combined influence of local circulations and momentum transfer from the background wind has also been suggested by Adler et al. (2011) to explain triggering of convection in response to prescribed soil moisture anomalies.

Second, once convection is initiated, the background wind supports the advection or propagation of the developing deep convective systems downwind, that is, from

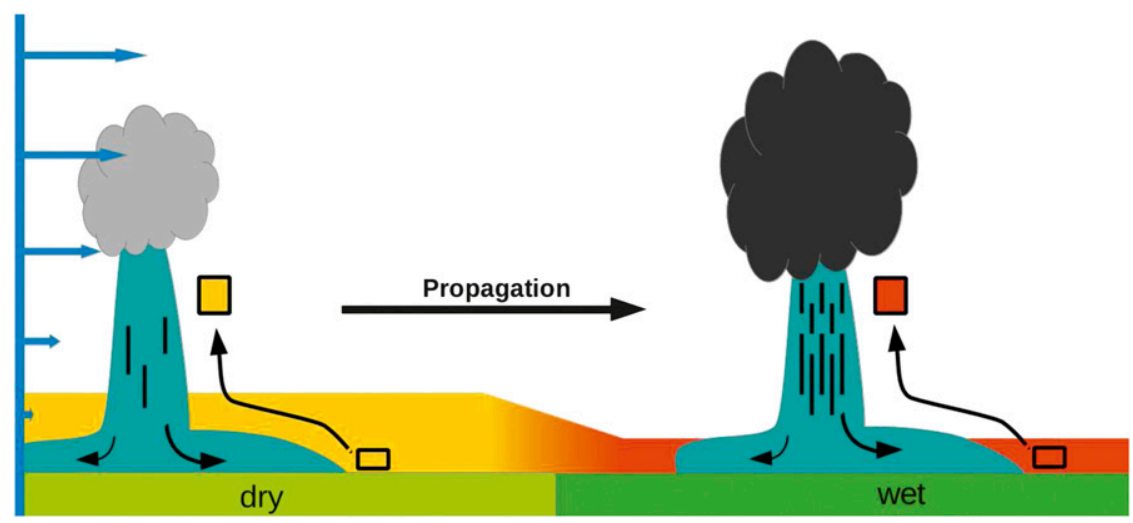

FIG. 12. Conceptual scheme of a mature convective system propagating over a soil moisture gradient. The PBL is shown in colors. Over the wet patch, the PBL is significantly shallower and PBL air contains more MSE. Red indicates higher values of MSE than does yellow. The mature convective system precipitates and induces a cold pool (shown in blue for relatively cooler temperature). Nearby surface parcels (rectangles) are forced to rise over the cold pool. They typically overpass their level of free convection so that deep convection is sustained. By propagating over a wet patch, the convective system encounters areas of higher surface MSE so that the lifted surface parcels are more buoyant and convection is significantly enhanced. The precipitation rate increases. 
dry to wet areas, so that the sign of the initially negative feedback loop is reversed.

Figure 12 depicts the influence of soil moisture anomalies on mature storms. Surface moist static energy (MSE) is higher over wet soils (red versus yellow colors) because of the concentration of higher total surface energy fluxes into a shallower PBL. Since the freetropospheric profile is not significantly affected by soil moisture gradients, surface parcels with a high MSE are systematically more buoyant once lifted to their LFC. Differences in CAPE amounting to several hundreds of joules per kilogram enhance substantially the convection when storms pass over wet areas. In essence, the background wind enables the exploitation of regions with low CIN (where it is comparatively easy to generate convection) and high CAPE (where convection can easily produce precipitation).

\section{Conclusions}

This study used an idealized cloud-resolving modeling framework to investigate the influence of the background wind on the local soil moisture-precipitation feedback over flat and homogeneous terrain. Simulations show the interaction between soil moisture anomalies, local circulations, and convective processes. Depending on environmental conditions, complex patterns of soil moisture and precipitation evolve. In all simulations, convection is initiated preferentially over drier areas, in association with local circulations along soil moisture gradients, and mainly upstream of wet patches. The background wind enables the developing cells to propagate downstream. Here they meet wet patches with high convective potential (CAPE), develop into mature convective storms, and precipitate. Consequently, a positive SMP feedback is found in simulations with background wind. When the background wind is set to zero, stationary storms produce rain at the location of convection initiation and the local SMP feedback turns negative. This study highlights the sensitivity of the feedback sign and strength upon the background wind speed. We also investigate the feedback mechanism in detail, with a focus on local circulations and cumulus development as well as surface energy balance considerations. It is argued that convective-scale feedback processes between soil moisture and atmospheric circulation is decisive to understand the large variability of the SMP feedbacks reported in previous studies.

Further investigations with this idealized model setup could help bridging the gap between real and idealized cases. Multidirectional wind profiles and the Coriolis force are likely to affect the storm dynamics and associated distribution of precipitation. It would moreover be interesting to identify and quantify the potential role of land surface and topographic heterogeneity.

A major shortcoming of the current setup is the constant synoptic forcing. Such a situation is not necessarily unrealistic but precipitation is often triggered by synoptic- or mesoscale features. In continental Europe for instance, diurnal circulations alone may imply summer precipitation even in the absence of strong forcing, but significant precipitation events are usually driven by synoptic disturbances. Similarly, in West Africa, rainfall occurs mostly in association with mesoscale convective systems. These elements are not accounted for in the current simulations. Our numerical setup should thus be regarded as a powerful tool for the understanding of the local mechanisms involved in the SMP feedback, but a direct comparison with observations is evidently limited. It might thus be attractive to extend the current modeling framework to more transient settings, when soil moisture anomalies and atmospheric circulations are not in equilibrium.

Acknowledgments. The Swiss National Supercomputing Centre (CSCS) is acknowledged for providing access to its high-performance compute clusters. Access to the COSMO model was kindly provided by the COSMO consortium and the CLM community. We would particularly like to acknowledge technical support by Daniel Lüthi and the staff of MeteoSwiss, the Center for Climate Systems Modeling (C2SM), and the German Weather Service (in particular Uli Blahak).

\section{REFERENCES}

Adler, B., N. Kalthoff, and L. Gantner, 2011: The impact of soil moisture inhomogeneities on the modification of a mesoscale convective system: An idealised model study. Atmos. Res., 101, 354-372.

Avissar, R., and Y. Liu, 1996: Three-dimensional numerical study of shallow convective clouds and precipitation induced by land surface forcing. J. Geophys. Res., 101, 7499-7518.

Baidya Roy, S., and R. Avissar, 2002: Impact of land use/land cover change on regional hydrometeorology in Amazonia. J. Geophys. Res., 107, 8037, doi:10.1029/2000JD000266.

Baldauf, M., A. Seifert, J. Förstner, D. Majewski, M. Raschendorfer, and T. Reinhardt, 2011: Operational convective-scale numerical weather prediction with the COSMO model: Description and sensitivities. Mon. Wea. Rev., 139, 3887-3905.

Barthlott, C., and N. Kalthoff, 2011: A numerical sensitivity study on the impact of soil moisture on convection-related parameters and convective precipitation over complex terrain. J. Atmos. Sci., 68, 2971-2987.

Betts, A. K., 2004: Understanding hydrometeorology using global models. Bull. Amer. Meteor. Soc., 85, 1673-1688.

- 2009: Land surface-atmosphere coupling in observations and models. J. Adv. Model. Earth Syst, 1, doi:10.3894/ JAMES.2009.1.4. 
and P. Viterbo, 2005: Land-surface, boundary layer, and cloud-field coupling over the southwestern Amazon in ERA-40. J. Geophys. Res., 110, D14108, doi:10.1029/2004JD005702.

- R. Desjardins, and D. Worth, 2013: Cloud radiative forcing of the diurnal cycle climate of the Canadian prairies. J. Geophys. Res. Atmos., 118, 8935-8953, doi:10.1002/jgrd.50593.

Catalano, F., and C.-H. Moeng, 2010: Large-eddy simulation of the daytime boundary layer in an idealized valley using the Weather Research and Forecasting numerical model. Bound.Layer Meteor., 137, 49-75.

Chagnon, F., R. Bras, and J. Wang, 2004: Climatic shift in patterns of shallow clouds over the Amazon. Geophys. Res. Lett., 31, L24212, doi:10.1029/2004GL021188.

Clark, D., C. Taylor, and A. Thorpe, 2004: Feedback between the land surface and rainfall at convective length scales. $J$. $H y$ drometeor., 5, 625-639.

Davies, H., 1976: A lateral boundary formulation for multi-level prediction models. Quart. J. Roy. Meteor. Soc., 102, 405-418.

Desborough, C., A. Pitman, and P. Iranneiad, 1996: Analysis of the relationship between bare soil evaporation and soil moisture simulated by 13 land surface schemes for a simple non-vegetated site. Global Planet. Change, 13, 47-56.

Dickinson, R. E., 1984: Modeling Evapotranspiration for ThreeDimensional Global Climate Models. Geophys. Monogr., Vol. 29, Amer. Geophys. Union, 58-72.

Doms, G., and J. Förstner, 2004: Development of a kilometer-scale NWP-system: LMK. COSMO Newsletter, No. 4, Consortium for Small-Scale Modeling, 159-167. [Available online at http:// www.cosmo-model.org/content/model/documentation/ newsLetters/newsLetter04/chp9-5.pdf.]

Emori, S., 1998: The interaction of cumulus convection with soil moisture distribution: An idealized simulation. J. Geophys. Res., 103, 8873-8884.

Findell, K., and E. Eltahir, 1997: An analysis of the soil moisturerainfall feedback, based on direct observations from Illinois. Water Resour. Res., 33, 725-735.

$\longrightarrow$, and —, 2003a: Atmospheric controls on soil moistureboundary layer interactions. Part II: Feedbacks within the continental United States. J. Hydrometeor., 4, 570-583.

- and 2003b: Atmospheric controls on soil moistureboundary layer interactions: Three-dimensional wind effects. J. Geophys. Res., 108, 8385, doi:10.1029/2001JD001515.

- P. Gentine, B. R. Lintner, and C. Kerr, 2011: Probability of afternoon precipitation in eastern United States and Mexico enhanced by high evaporation. Nat. Geosci., 4, 434-439.

Gantner, L., and N. Kalthoff, 2010: Sensitivity of a modelled life cycle of a mesoscale convective system to soil conditions over West Africa. Quart. J. Roy. Meteor. Soc., 136, 471-482.

Garcia-Carreras, L., D. Parker, and J. Marsham, 2011: What is the mechanism for the modification of convective cloud distributions by land surface-induced flows? J. Atmos. Sci., 68, 619-634.

Goutorbe, J., and Coauthors, 1994: HAPEX-Sahel: A large-scale study of land-atmosphere interactions in the semi-arid tropics. Ann. Geophys., 12, 53-64.

Heise, E., M. Lange, B. Ritter, and R. Schrodin, 2003: Improvement and validation of the multi-layer soil model. COSMO Newsletter, No. 3, Consortium for Small-Scale Modeling, 198-203. [Available online at http://www.cosmo-model.org/content/model/ documentation/newsLetters/newsLetter03/cnl3-chp9-12. pdf.]

Jarvis, P., 1976: The interpretation of the variations in leaf water potential and stomatal conductance found in canopies in the field. Philos. Trans. Roy. Soc. London, 273, 593-610.
Kalthoff, N., and Coauthors, 2011: The dependence of convectionrelated parameters on surface and boundary-layer conditions over complex terrain. Quart. J. Roy. Meteor. Soc., 137, 70-80.

Kang, S., and G. Bryan, 2011: A large eddy simulation study of moist convection initiation over heterogeneous surface fluxes. Mon. Wea. Rev., 139, 2901-2917.

Klemp, J., and R. Wilhelmson, 1978: The simulation of threedimensional convective storm dynamics. J. Atmos. Sci., 35, 1070-1096.

Koster, R., and Coauthors, 2004: Regions of strong coupling between soil moisture and precipitation. Science, 305, 1138-1140.

Langhans, W., and J. Schmidli, 2012: A Smagorinsky-Lilly turbulence closure for COSMO-LES: Implementation and comparison to ARPS. COSMO Newsletter, No. 12, Consortium for SmallScale Modeling, 20-31. [Available online at http://www.cosmomodel.org/content/model/documentation/newsLetters/ newsLetter12/newsLetter_12.pdf.]

— — - and C. Schär, 2012: Bulk convergence of cloudresolving simulations of moist convection over complex terrain. J. Atmos. Sci., 69, 2207-2228.

Louis, J., 1979: A parametric model of vertical eddy fluxes in the atmosphere. Bound.-Layer Meteor., 17, 187-202.

Mellor, G., and T. Yamada, 1974: A hierarchy of turbulence closure models for planetary boundary layers. J. Atmos. Sci., 31, 1791-1806.

Ookouchi, Y., M. Segal, R. Kessler, and R. Pielke, 1984: Evaluation of soil moisture effects on the generation and modification of mesoscale circulations. Mon. Wea. Rev., 112, 2281-2292.

Pielke, R., 2001: Influence of the spatial distribution of vegetation and soils on the prediction of cumulus convective rainfall. Rev. Geophys., 39, 151-177.

Raschendorfer, M., 2001: The new turbulence parameterization of LM. COSMO Newsletter, No. 1, Consortium for Small-Scale Modeling, 90-98. [Available online at http://www.cosmo-model. org/content/model/documentation/newsLetters/newsLetter01/ newsLetter_01.pdf.]

Reinhardt, T., and A. Seifert, 2006: A three-category ice scheme for LMK. COSMO Newsletter, No. 6, Consortium for SmallScale Modeling, 115-120. [Available online at http:/www.cosmomodel.org/content/model/documentation/newsLetters/ newsLetter06/cnl6_reinhardt.pdf.]

Ritter, B., and J. Geleyn, 1992: A comprehensive radiation scheme for numerical weather prediction models with potential applications in climate simulations. Mon. Wea. Rev., 120, 303-325.

Rockel, B., A. Will, and A. Hense, 2008: The regional climate model COSMO-CLM (CCLM). Meteor. Z., 17, 347-348.

Salvucci, G., J. Saleem, and R. Kaufmann, 2002: Investigating soil moisture feedbacks on precipitation with tests of Granger causality. Adv. Water Resour., 25, 1305-1312.

Schär, C., D. Lüthi, U. Beyerle, and E. Heise, 1999: The soilprecipitation feedback: A process study with a regional climate model. J. Climate, 12, 722-741.

— , P. Vidale, D. Lüthi, C. Frei, C. Häberli, M. Liniger, and C. Appenzeller, 2004: The role of increasing temperature variability in European summer heatwaves. Nature, 427, 332-336.

Schlemmer, L., C. Hohenegger, J. Schmidli, C. Bretherton, and C. Schär, 2011: An idealized cloud-resolving framework for the study of midlatitude diurnal convection over land. J. Atmos. Sci., 68, 1041-1057.

,,--- , and C. Schär, 2012: Diurnal equilibrium convection and land surface-atmosphere interactions in an idealized cloud-resolving model. Quart. J. Roy. Meteor. Soc., 138, 15261539. 
Schwendike, J., N. Kalthoff, and M. Kohler, 2010: The impact of mesoscale convective systems on the surface and boundary-layer structure in West Africa: Case-studies from the AMMA campaign 2006. Quart. J. Roy. Meteor. Soc., 136, 566-582.

Segal, M., and R. Arritt, 1992: Nonclassical mesoscale circulations caused by surface sensible heat-flux gradients. Bull. Amer. Meteor. Soc., 73, 1593-1604.

Seneviratne, S., D. Lüthi, M. Litschi, and C. Schär, 2006: Landatmosphere coupling and climate change in Europe. Nature, 443, 205-209.

Steppeler, J., G. Doms, U. Schättler, H. Bitzer, A. Gassmann, U. Damrath, and G. Gregoric, 2003: Meso-gamma scale forecasts using the nonhydrostatic model LM. Meteor. Atmos. Phys., 82, 75-96.

Taylor, C., and T. Lebel, 1998: Observational evidence of persistent convective-scale rainfall patterns. Mon. Wea. Rev., 126, $1597-1607$.

_ on convection at the mesoscale. Geophys. Res. Lett., 33, L03404, doi:10.1029/2005GL025252.

_ D. D. Parker, and P. Harris, 2007: An observational case study of mesoscale atmospheric circulations induced by soil moisture. Geophys. Res. Lett., 34, L15801, doi:10.1029/2007GL030572.
— P. Harris, and D. Parker, 2010: Impact of soil moisture on the development of a Sahelian mesoscale convective system: A case-study from the AMMA Special Observing Period. Quart. J. Roy. Meteor. Soc., 136, 456-470.

- , and Coauthors, 2011a: New perspectives on land-atmosphere feedbacks from the African Monsoon Multidisciplinary Analysis. Atmos. Sci. Lett., 12, 38-44.

, A. Gounou, F. Guichard, P. Harris, R. Ellis, F. Couvreux, and M. De Kauwe, 2011b: Frequency of Sahelian storm initiation enhanced over mesoscale soil-moisture patterns. Nat. Geosci., 4, 430-433.

Weaver, C. P., and R. Avissar, 2001: Atmospheric disturbances caused by human modification of the landscape. Bull. Amer. Meteor. Soc., 82, 269-281.

Wicker, L., and W. Skamarock, 2002: Time-splitting methods for elastic models using forward time schemes. Mon. Wea. Rev., 130, 2088-2097.

Wolters, D., C. van Heerwaarden, J. Vil-Guerau de Arellano, B. Cappelaere, and D. Ramier, 2010: Effects of soil moisture gradients on the path and the intensity of a West African squall line. Quart. J. Roy. Meteor. Soc., 136, 2162-2175.

Wyngaard, J., 2004: Toward numerical modeling in the Terra Incognita. J. Atmos. Sci., 61, 1816-1826. 